\title{
Structure and Electronic Properties of the Quasi-One-Dimensional
}

\section{$\mathrm{Ba}_{2} \mathrm{Co}_{1-\mathrm{x}} \mathrm{Zn}_{\mathrm{x}} \mathrm{S}_{3}$ Series}

Mark R. Harrison, ${ }^{1}$ Antoine Maignan, ${ }^{2}$ Vincent Hardy, ${ }^{2}$ Oleg I. Lebedev, ${ }^{2}$ Nigel A. Young ${ }^{1}$ and M. Grazia Francesconi ${ }^{*}$

1. School of Mathematics and Physical Science - G. W. Gray Centre for Advanced Materials Chemistry Building, University of Hull, Cottingham Road, Hull, HU6 7RX, UK. Corresponding author: m.g.francesconi@ull.ac.uk.

2 CRISMAT UMR 6508, CNRS-ENSICAEN, 6Bd Marechal Juin, 14050 Caen, France

This document is the Accepted Manuscript version of a Published Work that appeared in final form in Inorganic Chemistry, copyright (C) American Chemical Society after peer review and technical editing by the publisher.

To access the final edited and published work see [insert ACS Articles on Request author-directed link to Published Work, see http://pubs.acs.org/page/policy/articlesonrequest/index.html]. 


\begin{abstract}
This work focuses on the structure and physical properties of the solid solution $\mathrm{Ba}_{2} \mathrm{Co}_{1-\mathrm{x}} \mathrm{Zn}_{\mathrm{x}} \mathrm{S}_{3}$ $(0 \leq \mathrm{x} \leq 1)$, a family of quasi-one-dimensional sulfides with end members $\mathrm{Ba}_{2} \mathrm{CoS}_{3}$ and $\mathrm{Ba}_{2} \mathrm{ZnS}_{3}$. The structure of selected compounds with increasing $\mathrm{Zn}^{2+}$ content has been analysed using, neutron diffraction, TEM and EXAFS and the physical properties via magnetic susceptibility and resistivity measurements. The progressive substitution of the non-magnetic $\mathrm{Zn}^{2+}$ cation for $\mathrm{Co}^{2+}$ rapidly destroys the antiferromagnetic transition present at $46 \mathrm{~K}$ in the quasi one-dimensional $\mathrm{Ba}_{2} \mathrm{CoS}_{3}$, leading to paramagnetic behaviour down to the lowest investigated temperature $(5 \mathrm{~K})$ for compounds with $\mathrm{x}>0.25$. For compounds with $\mathrm{x} \geq 0.4$, a pure $\mathrm{CW}$ regime is recovered around $300 \mathrm{~K}$, yielding effective moments consistent with the $\mathrm{g}$ factor of the tetrahedrally coordinated $\mathrm{Co}^{2+}$ previously determined for $\mathrm{Ba}_{2} \mathrm{CoS}_{3}$. The $\mathrm{Zn}^{2+} / \mathrm{Co}^{2+}$ substitution also removes the metallic-like behaviour of $\mathrm{Ba}_{2} \mathrm{CoS}_{3}$ causing an increase in the value of the resistivity with all the $\mathrm{Ba}_{2} \mathrm{Co}_{1-\mathrm{x}} \mathrm{Zn}_{\mathrm{x}} \mathrm{S}_{3}$ compounds showing semiconducting behaviour. The negative magnetoresistance of $\mathrm{Ba}_{2} \mathrm{CoS}_{3}$ is improved by the $\mathrm{Zn}^{2+} / \mathrm{Co}^{2+}$ substitution, with values of $-6 \%$ for $\mathrm{Ba}_{2} \mathrm{Co} 0.75 \mathrm{Zn} 0.25 \mathrm{~S}_{3},-9 \%$ for $\mathrm{Ba}_{2} \mathrm{Co} 0.5 \mathrm{Zn} 0.5 \mathrm{~S}_{3}$ and $-8 \%$ for $\mathrm{Ba}_{2} \mathrm{Co} 0.25 \mathrm{Zn} 0.75 \mathrm{~S}_{3}$. However, there does not seem to be a correlation between the values of the resistivity and the magnetoresistance and the content of $\mathrm{Zn}^{2+}$, leading to the hypothesis that transport properties may be linked more closely to extrinsic properties.
\end{abstract}




\section{Introduction}

Sulfides are a class of relatively under explored compounds compared to oxides, due, in part, to the greater experimental requirements of non-oxide synthesis but also to the enormous interest constantly devoted to the chemistry of oxides. However, with progress in preparation methods, the investigation of non-oxide materials has gained pace, fuelled by the interesting and often unique structural and physical properties they reveal. ${ }^{1}$

The higher polarisability of the sulfide ion, relative to the oxide ion, ensures that sulfides are in general less ionic than oxides, and therefore low-dimensional structures are encountered more frequently in sulfides. In fact these materials can make an important contribution to the study of low-dimensional magnetic interactions in solids. The characterisation of onedimensional materials is particularly welcome, as these systems are rarer than two-dimensional materials. $^{2}$

One group of compounds, investigated for their quasi-one-dimensional magnetic structures, is the $\mathrm{Ba}_{2} \mathrm{MS}_{3}(\mathrm{M}=\mathrm{Mn}, \mathrm{Fe}, \mathrm{Co}, \mathrm{Zn}, \mathrm{Cd}, \mathrm{Hg})$ series.

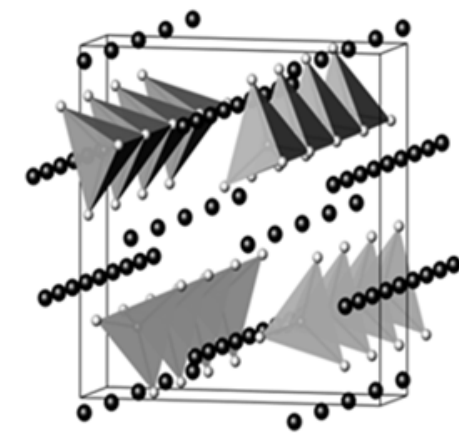

a

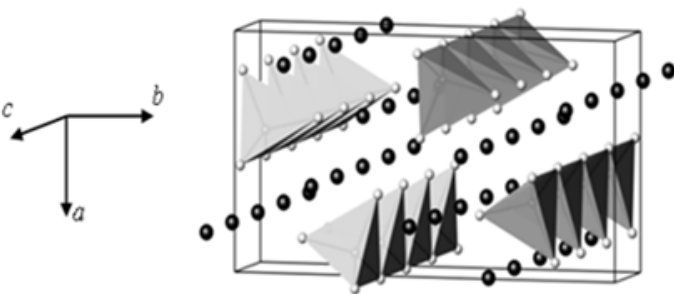

$\mathrm{b}$

Figure 1. Structure of (a) $\mathrm{Ba}_{2} \mathrm{MS}_{3}(\mathrm{M}=\mathrm{Zn}, \mathrm{Co}, \mathrm{Fe})$ and (b) $\mathrm{Ba}_{2} \mathrm{MS}_{3}(\mathrm{M}=\mathrm{Mn}, \mathrm{Hg}, \mathrm{Cd})$. The dark gray and light gray spheres represent the barium and sulfur respectively. The gray polyhedra are transition metal centred.

Two families of structurally similar sulfides show this 213 stoichiometry: $\mathrm{Ba}_{2} \mathrm{MS}_{3}$ with $\mathrm{M}=$ $\mathrm{Mn}, \mathrm{Hg}, \mathrm{Cd}$ and $\mathrm{Ba}_{2} \mathrm{MS}_{3}$ with $\mathrm{M}=\mathrm{Fe}, \mathrm{Co}, \mathrm{Zn}^{3,4}$ Both $\mathrm{Ba}_{2} \mathrm{MS}_{3}$ families show one-dimensional chains of corner linked M-S tetrahedra interleaved by $\mathrm{Ba}^{2+}$ cations and two crystallographically different sites for $\mathrm{Ba}^{2+}$. However, $\mathrm{Ba}_{2} \mathrm{MS}_{3}(\mathrm{M}=\mathrm{Fe}, \mathrm{Co}, \mathrm{Zn})$ show the $\mathrm{K}_{2} \mathrm{CuCl}_{3}$-type structure, while $\mathrm{Ba}_{2} \mathrm{MS}_{3}(\mathrm{M}=\mathrm{Mn}, \mathrm{Hg}, \mathrm{Cd})$ show the $\mathrm{K}_{2} \mathrm{AgI}_{3}$-type structure. $\mathrm{Ba}_{2} \mathrm{MnS}_{3}$ is insulating with a room temperature resistivity of $10^{2}-10^{3} \Omega \mathrm{cm}^{5}$ The resistivity of $\mathrm{Ba}_{2} \mathrm{CoS}_{3}$ is much lower at $\sim 10^{-1} \Omega \mathrm{cm}$ and thermopower measurements were indicative of metallic like conduction. ${ }^{6} \mathrm{An}$ investigation into $\mathrm{Ba}_{2} \mathrm{FeS}_{3}$ suggests limited electron delocalisation. The high resistivity $\left(10^{4}\right.$ $\Omega \mathrm{cm}$ ), the effective magnetic moment of $5.29 \mu_{\mathrm{B}}$ and Mössbauer spectroscopy suggest that iron is present as $\mathrm{Fe}^{2+}$ ? 
$\mathrm{Ba}_{2} \mathrm{ZnS}_{3}$ was first synthesised by Schnering and Hoppe in 1961 who found an orthorhombic unit cell of space group 62, Pnma, with parameters of $a=12.05 \AA, b=12.65 \AA$ and $c=4.21$ $\AA$ (no standard deviations were quoted). ${ }^{8} \mathrm{Ba}_{2} \mathrm{CoS}_{3}$ was first synthesised by Hong and Steinfink in a 1972 investigation into Ba-Fe-S phases, and was found to be isostructural to $\mathrm{Ba}_{2} \mathrm{FeS}_{3}$ and $\mathrm{Ba}_{2} \mathrm{ZnS}_{3}{ }^{9}$ An investigation into the magnetic susceptibilities of $\mathrm{Ba}_{2} \mathrm{FeS}_{3}, \mathrm{Ba}_{2} \mathrm{CoS}_{3}$ and $\mathrm{Ba}_{2} \mathrm{MnS}_{3}$ showed features consistent with quasi-one-dimensional antiferromagnetic shortrange ordering. ${ }^{10}$ Intrachain interactions, $\mathrm{J}$, of $-20,-15$ and $-12 \mathrm{~K}$ (in good agreement with value of $-12.3(5) \mathrm{K}$ previously reported for $\mathrm{Ba}_{2} \mathrm{MnS}_{3}$ and $\mathrm{Ba}_{2} \mathrm{MnSe}_{3}$ ) were found for $\mathrm{Ba}_{2} \mathrm{FeS} 3$, $\mathrm{Ba}_{2} \mathrm{CoS}_{3}$ and $\mathrm{Ba}_{2} \mathrm{MnS}_{3}{ }^{11}$ Long range magnetic ordering was found for all three compounds at 4.2 $\mathrm{K}$ due to inter-chain interactions. ${ }^{10}$ The magnetic susceptibility of $\mathrm{Ba}_{2} \mathrm{CoS}_{3}$ has been reinvestigated and the data again showed a broad peak indicative of quasi-one-dimensional magnetic ordering but also a transition to long range order, at $46 \mathrm{~K} .{ }^{12,13,14}$ Interestingly, $\mathrm{Ba}_{2} \mathrm{CoS}_{3}$ shows negative magnetoresistance, $\mathrm{MR} \sim-1.7 \%$ in a $7 \mathrm{~T}$ field at $10 \mathrm{~K}$ which is higher than that of the only other one dimensional sulfide so far reported to show MR. ${ }^{6}$ Recently, it was reported that this negative magnetoresistance can be increased up to $9 \%$ via partial isovalent substitution of $\mathrm{Co}^{2+}$ with the diamagnetic $\mathrm{Zn}^{2+} \cdot 15$

In order to identify trends in the electronic properties and relationships between chemical composition and structure of these sulfides and their magnetic and transport properties, we studied a larger number of members of the solid solution $\mathrm{Ba}_{2} \mathrm{Co}_{1-\mathrm{x}} \mathrm{Zn}_{\mathrm{x}} \mathrm{S}_{3}(0 \leq \mathrm{x} \leq 1)$. Our results show that, whereas there are clearly identifiable trends between the magnetic properties and the $\mathrm{Zn}$ content in the samples of the $\mathrm{Ba}_{2} \mathrm{Co}_{1-\mathrm{x}} \mathrm{Zn}_{\mathrm{x}} \mathrm{S}_{3}$ series, similar correlations cannot be found for the transport properties.

\section{Experimental}

The synthesis of the ternary sulfides $\mathrm{Ba}_{2} \mathrm{Co}_{1-\mathrm{x}} \mathrm{Zn}_{\mathrm{x}} \mathrm{S}_{3}(\mathrm{x}=0.1,0.2,0.25,0.4,0.5,0.6,0.75,0.8)$ was achieved via a solid-gas reaction. Stoichiometric mixtures of barium carbonate $(99 \%)$ cobalt $(99.8 \%)$ and zinc oxide $(99.8 \%)$ were reacted with carbon disulfide $(99 \%)$ for 24 hours at $1000^{\circ} \mathrm{C}$.

Time-of-flight (TOF) neutron powder diffraction (NPD) data were collected on selected samples on the Polaris beamline at the ISIS neutron source at the Rutherford Appleton Laboratory. Approximately $5 \mathrm{~g}$ of sample was loaded into vanadium sample cans. Data for $\mathrm{Ba}_{2} \mathrm{Co} 0.5 \mathrm{Zn} 0.5 \mathrm{~S}_{3}$ was collected at $\sim 4 \mathrm{~K}$ with all other samples run at room temperature.

Co K-edge and Zn K-edge XAS measurements were performed at station 9.3 of the Daresbury Laboratory SRS operating at $2 \mathrm{GeV}$ with 100-250 mA circulating currents. The Co and Zn Kedge energies were obtained using a $\mathrm{Si}(111)$ double crystal monochromator, and harmonic rejection used a Pd coated mirror. The samples were diluted in boron nitride and the data collected in transmission mode at ca. $80 \mathrm{~K}$. The spectra were calibrated using the first maximum in the first derivative of Co $(7709.0 \mathrm{eV})$ or $\mathrm{Zn}(9659.0 \mathrm{eV})$ foils.

Averaging and calibration (using monochromator position) of the spectra was achieved within PAXAS, ${ }^{16}$ and background subtraction employed PySpline. ${ }^{17}$ The pre-edge peak positions were taken as the maximum of the peak/crossing point in the first derivative, whereas the edge 
position was taken as the maximum of the first derivative in the edge region. The EXAFS data were fitted using curved wave, single scattering theory within EXCURV98. ${ }^{18}$ The quality of fit is indicated by an R-factor, but the statistical significance of including additional shells made use of the reduced $\chi^{2}$ function within EXCURV98. The inter-atomic distances, Debye-Waller factors and $\mathrm{E}_{\mathrm{f}}$ were refined. The Debye-Waller factor is a measure of the variation in atomic distances and accounts for the molecular structural and thermal disorder of a sample. For closely separated shells of the same back-scatterer the values were constrained to be equal. $\mathrm{E}_{\mathrm{f}}$ is a measure of the difference between the experimental and calculated Fermi energies.

Magnetic susceptibility curves were recorded on polycrystalline samples, upon warming from 5 to $300 \mathrm{~K}$ after a zero-field cooling. These measurements were conducted in Quantum Design PPMS and MPMS magnetometers, using magnetic fields equal to 3000 and 100 Oe, respectively.

Resistivity measurements (four-probe technique) were recorded in the temperature range 5 $400 \mathrm{~K}$ and in magnetic field of strength ranging $0 \mathrm{~T}$ and $7 \mathrm{~T}$. Four electrical contacts of silver paste were deposited on bar shaped samples having typical dimensions of $2 \times 2 \times 10 \mathrm{~mm}$. Due to a lack of an efficient sintering system, the typical apparent density led to rather poor compactness values ( $60-70 \%)$. Accordingly, the grain boundaries contribution was taken into account in the subsequent evaluation of the results. Isothermal magnetoresistance was measured by sweeping the magnetic field between $0 \mathrm{~T}$ and $7 \mathrm{~T}$. The magnetoresistance was calculated by using the relation $\mathrm{MR}=100 \times\left[\left(\rho_{\mathrm{H}}-\rho_{\mathrm{H}=0}\right) / \rho_{\mathrm{H}=0}\right](1)$.

Electron diffraction (ED) and high resolution transmission electron microscopy (HRTEM) were carried out with a Tecnai G2 30 UT microscope operated at $300 \mathrm{kV}$ and with $0.17 \mathrm{~nm}$ point resolution on powders, dissolved in butanol and deposited on a holey carbon grid. EDX analysis was performed with an energy-dispersive X-ray spectrometer (EDX) system attached to Tecnai G2 30 UT microscope.

\section{Results and Discussion}

\section{Neutron Powder Diffraction (NPD)}

All of the samples in the series $\mathrm{Ba}_{2} \mathrm{Co}_{1-x} \mathrm{Zn}_{\mathrm{x}} \mathrm{S}_{3}(\mathrm{x}=0.1,0.2,0.25,0.4,0.5,0.6,0.75,0.8)$ were analysed using Powder X-Ray diffraction (PXRD). Search match software was used to determine the purity of the samples. Small impurities of $\mathrm{BaS}$ were found in some samples and could not be eliminated upon further heating. ${ }^{19}$ No corresponding impurities containing $\mathrm{Zn}$ or Co were seen in the PXRD data. Examples of PXRD patterns were published in reference 15.

For the refinement of NPD data, three detection banks were used and all three histograms produced were analysed simultaneously using the software package GSAS. ${ }^{20,}{ }^{21}$ In this paper, we show only the refinement performed on the bank with the best resolution (up to $3 \AA$, dspacing).

The structure of $\mathrm{Ba}_{2} \mathrm{CoS}_{3}$ was chosen as the starting model with $\mathrm{Zn}$ and Co located on the same site and the fractional occupancies set initially to the values dictated by the stoichiometry of 
the starting material. The scale, cell parameters, atomic positions (with the atomic positions of $\mathrm{Zn}$ and Co constrained to be equal) and peak profile ( $\sim 5$ terms) were all refined. Analysis showed that $\mathrm{BaS}$ is present as an impurity in all sample at $<3 \%$ weight. There is also some evidence for an amorphous impurity in the broad peaks seen at $1.226 \AA$ and $2.097 \AA$ (in dspacing) in some of the neutron diffraction patterns. This amorphous impurity could contain the excess transition metal resulting from the formation of $\mathrm{BaS}$.

An example of a refinement is shown in figure 2 with the atomic positions, thermal parameters and occupancies for $\mathrm{Ba}_{2} \mathrm{Co}_{0.75} \mathrm{Zn}_{0.25} \mathrm{~S}_{3}$ shown in table 1. A summary of the unit cell parameters for all the samples along with the residual fit parameters is shown in table 2.

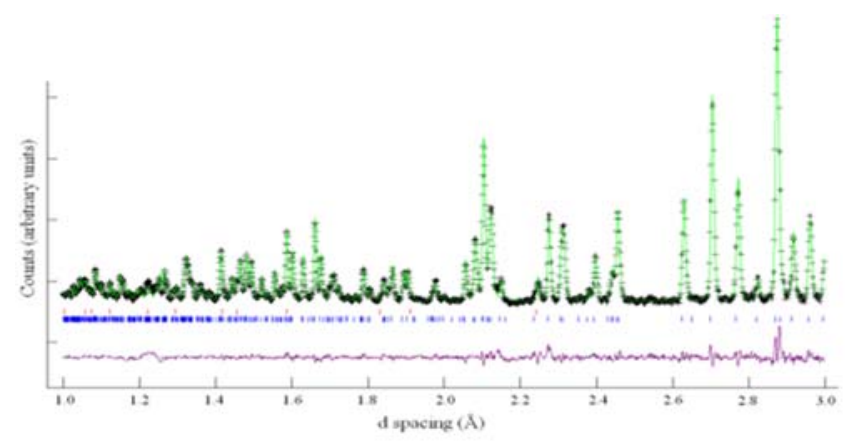

Figure 2. Rietveld refinement against neutron diffraction data for $\mathrm{Ba}_{2} \mathrm{Co}_{0.75} \mathrm{Zn} 0.25 \mathrm{~S}_{3}$ : Black crosses (observed), green line (calculated) and purple line (difference). Blue tick marks correspond to $\mathrm{Ba}_{2} \mathrm{Co}_{0.75} \mathrm{Zn}_{0.25} \mathrm{~S}_{3}$ (98.5 \% weight) and red to $\mathrm{BaS}$ (1.5\% weight).

\begin{tabular}{llllll}
\hline Atom & $\mathrm{x}$ & $\mathrm{y}$ & $\mathrm{z}$ & $\mathrm{U}$ & $\mathrm{F}$ \\
\hline $\mathrm{Ba} 1$ & $0.8285(1)$ & $0.4808(1)$ & 0.25 & $0.0090(3)$ & 1 \\
$\mathrm{Ba} 2$ & $0.4882(1)$ & $0.6730(1)$ & 0.25 & $0.0057(2)$ & 1 \\
Co & $0.7488(2)$ & $0.1984(2)$ & 0.25 & $0.0030(4)$ & $0.784(8)$ \\
Zn & $0.7488(2)$ & $0.1984(2)$ & 0.25 & $0.0030(4)$ & $0.216(8)$ \\
S1 & $0.8649(2)$ & $0.0526(2)$ & 0.25 & $0.0129(6)$ & 1 \\
S2 & $0.5612(2)$ & $0.1410(2)$ & 0.25 & $0.0036(4)$ & 1 \\
S3 & $0.2279(2)$ & $0.7111(2)$ & 0.25 & $0.0029(4)$ & 1 \\
\hline
\end{tabular}

Table 1. Refined atomic coordinates, thermal parameters and occupancies for $\mathrm{Ba}_{2} \mathrm{Co} 0.75 \mathrm{Zn} 0.25 \mathrm{~S}_{3}$ from neutron diffraction data. 


\begin{tabular}{lllll}
\hline $\mathrm{x}$ & $0^{13}$ & 0.1 & 0.25 & 0.75 \\
\hline$a(\AA)$ & $11.994(2)$ & $11.9975(5)$ & $11.9987(3)$ & $11.9980(2)$ \\
$b(\AA)$ & $12.472(2)$ & $12.4843(6)$ & $12.5033(3)$ & $12.5601(3)$ \\
$c(\AA)$ & $4.201(1)$ & $4.2059(2)$ & $4.2067(1)$ & $4.20844(8)$ \\
$V\left(\AA^{3}\right)$ & $628.5(3)$ & $629.96(7)$ & $631.10(4)$ & $634.20(3)$ \\
$R_{p}$ & 5.14 & 4.18 & 3.18 & 3.64 \\
$R_{w p}$ & 4.03 & 2.58 & 2.30 & 2.12 \\
$\chi^{2}$ & 5.06 & 2.66 & 3.94 & 3.07
\end{tabular}

Table 2. Summary of lattice parameters and residual fit parameters from neutron data for $\mathrm{Ba}_{2} \mathrm{Co}_{1-\mathrm{x}} \mathrm{Zn}_{\mathrm{x}} \mathrm{S}_{3}$. All diffraction patterns were collected at room temperature.

With the effective ionic radius for $\mathrm{Zn}^{2+}$ only slightly larger ( $0.60 \AA$ in tetrahedral coordination) than that of $\mathrm{Co}^{2+}(0.58 \AA \text { in tetrahedral coordination })^{22}$ the unit cell parameters do not show a detectable linear variation expected from Vegard's Law.

The diffraction pattern of $\mathrm{Ba}_{2} \mathrm{Co}_{0.5} \mathrm{Zn}_{0.5} \mathrm{~S}_{3}$ was collected at $\sim 4 \mathrm{~K}$ ( $a=11.9756(4) \AA, b=$ 12.5013(5) $\left.\AA, c=4.1965(2) \AA ; R_{p}=2.42, R_{w p}=1.45, \chi^{2}=3.94\right)$ to determine the possible existence of a transition to three-dimensional magnetic order in analogy to $\mathrm{Ba}_{2} \mathrm{CoS}_{3}$, which shows such a transition at $\mathrm{T}_{\mathrm{N}}=46 \mathrm{~K}$. However, no magnetic transition was detected for $\mathrm{Ba}_{2} \mathrm{Co}_{0.5} \mathrm{Zn}_{0.5} \mathrm{~S}_{3}$ down to $4 \mathrm{~K}$. (Supplementary Information, Figure 1 and Table 1)

\section{X-ray Absorption Spectroscopy (XAS)}

X-ray absorption spectroscopy can give element specific information about the oxidation state and local coordination environment from the XANES and the local (average) structural environment from the EXAFS.

\section{XANES}

The energy of pre-edge features and the edge itself in XANES spectra are diagnostic of oxidation state. The intensity of pre-edge features, usually assigned to $1 \mathrm{~s}-3 \mathrm{~d}$ transitions, is dependent both on the number of vacancies in the valence $3 \mathrm{~d}$ orbitals and on the coordination environment, with centro-symmetric geometries such as octahedral having weaker pre-edge features than tetrahedral geometries. The presence of a peak or distinct shoulder on the edge 
itself is caused by $1 s-4 p$ transitions and is generally indicative of square planar or square based pyramidal centres. ${ }^{14}$ The Co K-edge XANES spectrum of $\mathrm{Ba}_{2} \mathrm{CoS}_{3}$ has been studied previously and the relatively intense pre-edge feature at $7708.6 \mathrm{eV}$, together with the lack of shoulders or peaks on the edge was used to confirm the presence of a distorted tetrahedral environment. ${ }^{14}$ The striking similarity of a spectrum of $\mathrm{Ba}_{2} \mathrm{CoS}_{3}$ and its $1^{\text {st }}$ derivative (Figure 3(a) with the spectra and first derivatives for the $\mathrm{Ba}_{2} \mathrm{Co}_{1-\mathrm{x}} \mathrm{Zn}_{\mathrm{x}} \mathrm{S}_{3}(\mathrm{x}=0.25,0.5,0.75)$ series (Figure $3(\mathrm{~b}-\mathrm{d})$ ) confirms that a distorted tetrahedral environment is maintained upon substitution of $\mathrm{Zn}$ for Co at all values of $x$ studied.
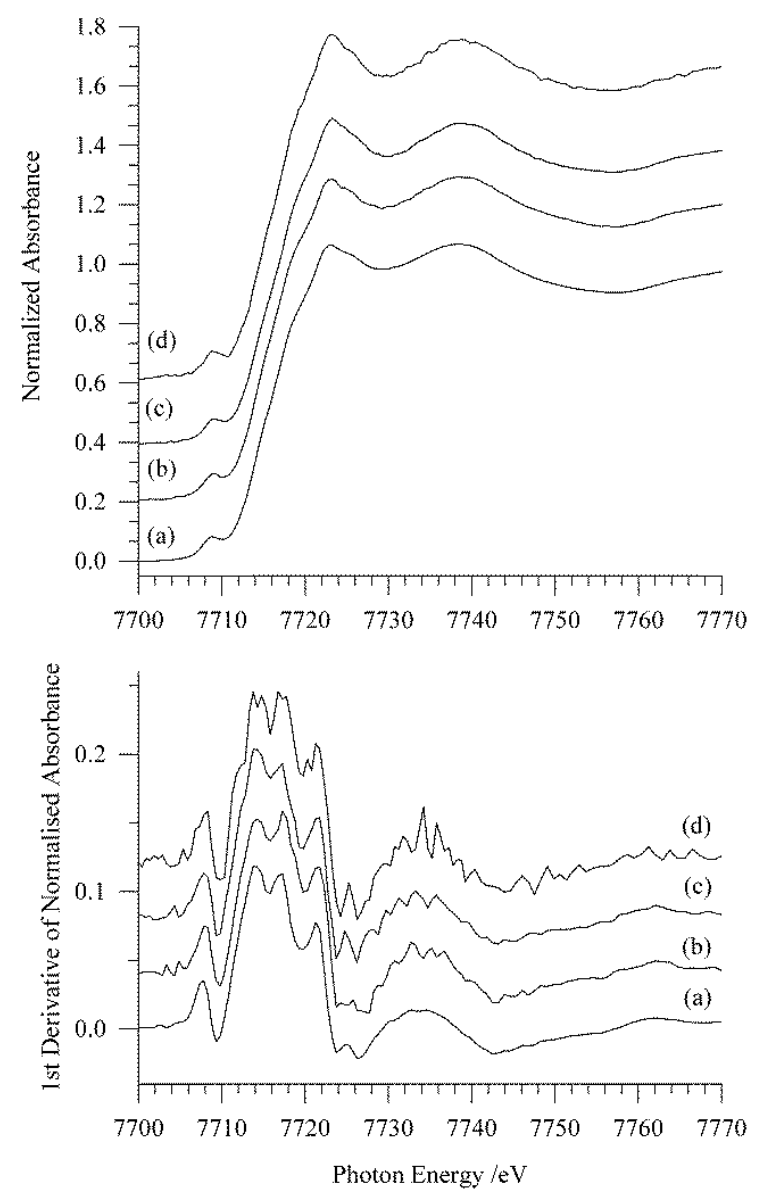

Figure 3. Co K-edge XANES spectra (top) and $1^{\text {st }}$ derivative (bottom) of (a) $\mathrm{Ba}_{2} \mathrm{CoS}_{3}$ (b) $\mathrm{Ba}_{2} \mathrm{Co}_{0.75} \mathrm{Zn}_{0.25} \mathrm{~S}_{3}$ (c) $\mathrm{Ba}_{2} \mathrm{Co}_{0.5} \mathrm{Zn}_{0.5} \mathrm{~S}_{3}$ and (d) $\mathrm{Ba}_{2} \mathrm{Co}_{0.25} \mathrm{Zn}_{0.75} \mathrm{~S}_{3}$.

Although the Zn K-edge XANES region lacks the 1s-3d transitions, which can be used diagnostically in Co K-edge spectra to identify the coordination environment, the edge structure itself is sensitive to coordination number. For example, a relatively intense "whiteline" is observed for octahedral coordination, but in tetrahedral geometries, this is much less intense, and also at slightly lower energy for sulfur ligation. ${ }^{23}$ 
The $\mathrm{Zn} \mathrm{K}$-edge of $\mathrm{Ba}_{2} \mathrm{ZnS}_{3}$ has not previously been studied, but the spectra in Figure 4 are very similar to those reported for other $\mathrm{ZnS}_{4}$ coordination environments, ${ }^{24,25}$ and the close similarity to that of $\mathrm{ZnS}$ confirms a tetrahedral $\mathrm{ZnS}_{4}$ coordination environment in $\mathrm{Ba}_{2} \mathrm{ZnS}_{3}$. The spectra and the $1^{\text {st }}$ derivatives for several members across a wide composition range are essentially identical, indicating that there is very little change when the $\mathrm{Zn}$ is substituted by Co.

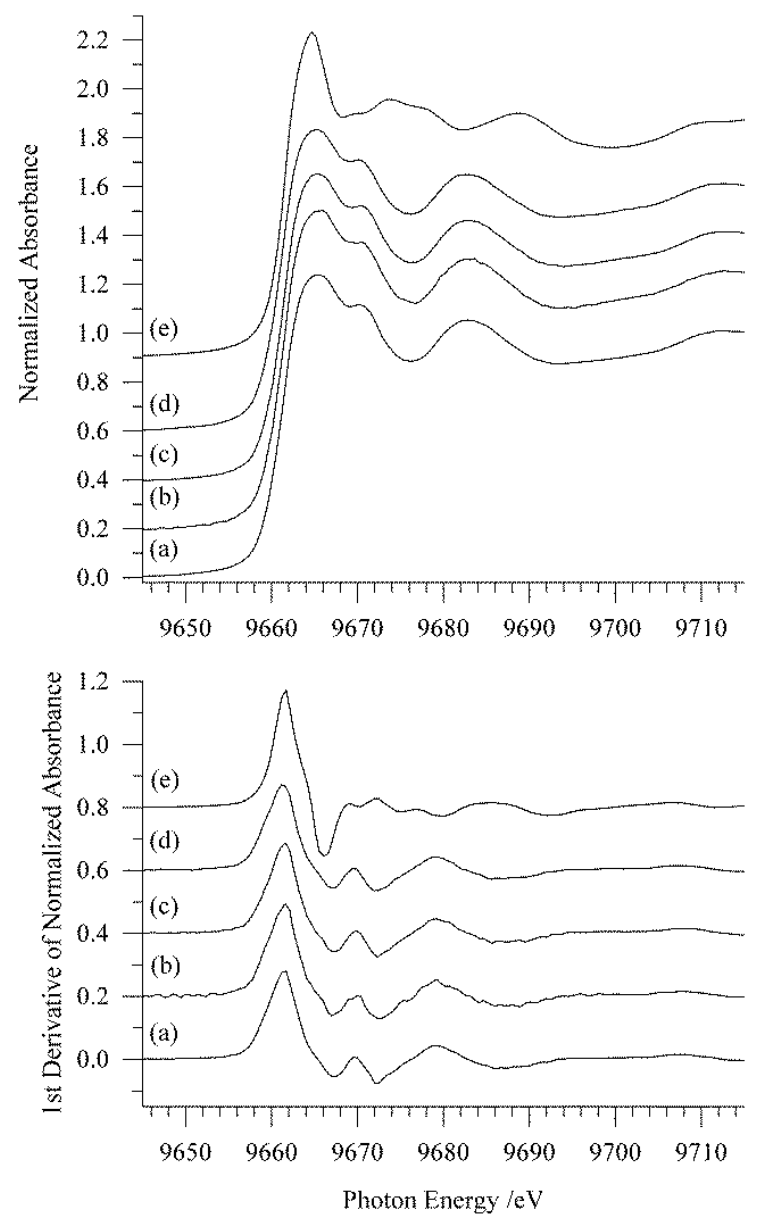

Figure 4. Zn K-edge XANES spectra (top) and $1^{\text {st }}$ derivatives (bottom) of (a) $\mathrm{Ba}_{2} \mathrm{ZnS}_{3}$, (b) $\mathrm{Ba}_{2} \mathrm{Co}_{0.75} \mathrm{Zn}_{0.25} \mathrm{~S}_{3}$, (c) Ba2 Co0.5Zn $0.5 \mathrm{~S}_{3}$, (d) $\mathrm{Ba}_{2} \mathrm{Co}_{0.25} \mathrm{Zn}_{0.75} \mathrm{~S}_{3}$, and (e) $\mathrm{ZnS}$.

\section{EXAFS}

Although EXAFS provides an average description of the local structure, it is element specific, so will be able to detect any changes occurring around either the Co or the $\mathrm{Zn}$. For the analysis of EXAFS data the local environment of the transition metal (TM) was initially set using the parameters for a five shell fit obtained from the previous study of the Co K-edge EXAFS data for $\mathrm{Ba}_{2} \mathrm{CoS}_{3}$ and from XRD data. ${ }^{14}$ The first TM-S shell in the Fourier transform (FT) was set as a single shell of four sulfur atoms at a radius of $2.35 \AA$ as the previous study showed that EXAFS cannot resolve the subtle differences between the M-S distances obtained from XRD data. The next significant shell is made up of seven TM-Ba interactions, (two at $3.515 \AA$, one 
at $3.693 \AA$, two at $3.855 \AA$ and two at $3.856 \AA$ ) and by two TM-TM interactions (at $4.1 \AA$ ). As previously, these were modelled by three TM-Ba at $3.5 \AA$, four TM-Ba at $3.8 \AA$ and two TM$\mathrm{TM}$ at $4.1 \AA$, with the Debye-Waller factors for the two TM-Ba shells constrained to be equal during the refinement. Even with this approach these overlapping shells are a challenge to analyse due to the significant correlation between the amplitude parameters, and in some cases relatively large uncertainties in the refined Debye-Waller factors are a consequence of this. Therefore, care needs to be used to avoid over interpretation of the data. There appears to be evidence in the FTs of the Co K-edge data for two further TM-S interactions at around $5 \AA$ and whilst these could be modelled with some success, analysis of the reduced $\chi^{2}$ values indicated that the fits were not statistically significant. The final shell in the FT to be fitted was that at about $5.7 \AA$ resulting from another TM-Ba shell with occupation number 4 . Therefore, the fits and table of data refer to a 5 shell fit rather than a 7 shell fit. The results for the Co K-edge of $\mathrm{Ba}_{2} \mathrm{Co} 0.5 \mathrm{Zn}_{0.5} \mathrm{~S}_{3}$ are shown in Figure 5(a) and the results of the refinements are shown in table 3. Co K-edge EXAFS and FTs for $\mathrm{Ba}_{2} \mathrm{CoS}_{3}, \mathrm{Ba}_{2} \mathrm{Co}_{0.75} \mathrm{Zn}_{0.25} \mathrm{~S}_{3}$ and $\mathrm{Ba}_{2} \mathrm{Co}_{0.25} \mathrm{Zn}_{0.75} \mathrm{~S}_{3}$ are shown in the supplementary information. In the Zn K-edge data, the more distant shells in the FTs beyond $5 \AA$ are less well defined than in the Co K-edge data, but have been retained in the refinements to provide consistency. The results for the $\mathrm{Zn} \mathrm{K}$-edge of $\mathrm{Ba}_{2} \mathrm{Co}_{0.5} \mathrm{Zn}_{0.5} \mathrm{~S}_{3}$ are also given in figure 5(b) and the results of the refinements are shown in table 3. Zn K-edge EXAFS and FTs for $\mathrm{Ba}_{2} \mathrm{ZnS}_{3}, \mathrm{Ba}_{2} \mathrm{Co}_{0.25} \mathrm{Zn}_{0.27} \mathrm{~S}_{3}$ and $\mathrm{Ba}_{2} \mathrm{Co}_{0.75} \mathrm{Zn}_{0.25} \mathrm{~S}_{3}$ are shown in the Supplementary Information (Figures 2 and 3).

There is a striking similarity between all the Co K-edge data and all of the Zn K-edge data, apart from an expected increase in the noise level as the $\mathrm{Co}(\mathrm{Zn})$ fraction is reduced. The refined parameters from each edge are very similar for all compositions, with no significant variations in the M-S or M-Ba distances observed on changing the Co:Zn ratio. The data is in good agreement with the previously published X-ray diffraction data ${ }^{15}$ as well as the neutron data above. As expected the Co-S and Zn-S distances are slightly different (2.33(3) $\AA$ vs 2.37(3) $\AA))$ as are the Co...Co (4.08(6) $\AA$ ) and Zn...Zn (4.15(6) $\AA$ ) distances, confirming that EXAFS is a local element specific structural tool. Whilst the Co...Ba and $\mathrm{Zn}$...Ba distances are more similar, it needs to be remembered that there are a spread of distances expected even in the stoichiometric samples. The M...M distances might be expected to be sensitive to the change in the Co: $\mathrm{Zn}$ ratio in the samples, and to give insight into whether there is random substitution or clustering. Although there appears to be a shortening of both the $\mathrm{Co} . . \mathrm{Co} / \mathrm{Zn}$ and $\mathrm{Zn} . . . \mathrm{Zn} / \mathrm{Co}$ distances with increasing substitution, they do not change monotonically with composition. These changes are at the margins of the resolution possible with EXAFS, especially for such distant shells that are in close proximity to others. Attempts were made to refine the different $\mathrm{Co} . . . \mathrm{Co} / \mathrm{Zn}$ and $\mathrm{Zn} . . . \mathrm{Zn} / \mathrm{Co}$ contributions in the mixed samples, but because of the similarity of the Co and $\mathrm{Zn}$ back-scattering properties and overlapping of multiple shells this was not successful, in order to maintain consistency they were refined as single shells in all cases. Therefore, we conclude that it is not possible to use these data diagnostically to check for random substitution or clustering. The change in relative peak heights in the FTs of the Co and $\mathrm{Zn}$ EXAFS could be due to subtle differences in the interference effects of the M...Ba and M...M interactions, but the Debye-Waller factors for the $\mathrm{Zn}-\mathrm{S}$ interactions are slightly larger than those for the Co-S interactions for all compositions, indicating a higher level of disorder 
in the former compared to the latter. Therefore, whilst the agreement between both the Co and Zn K-edge EXAFS and XANES data with the X-ray and neutron diffraction data out to $5.5 \AA$ confirms the structure of $\mathrm{Ba}_{2} \mathrm{CoS}_{3}$ and $\mathrm{Ba}_{2} \mathrm{ZnS}_{3}$ is maintained with throughout the $\mathrm{Ba}_{2} \mathrm{Co}_{1-\mathrm{x}} \mathrm{Zn}_{\mathrm{x}} \mathrm{S}_{3}$ solid solution, there does not appear to be any systematic changes in the distances that could be used to identify random substitution or clustering of the impurity.

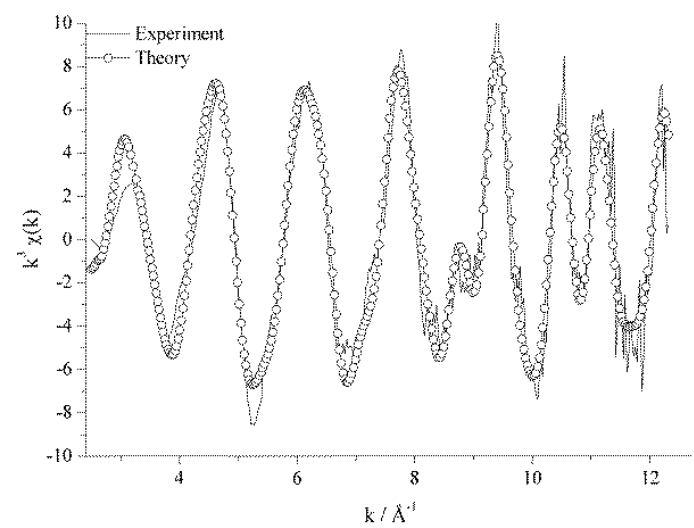

(a)
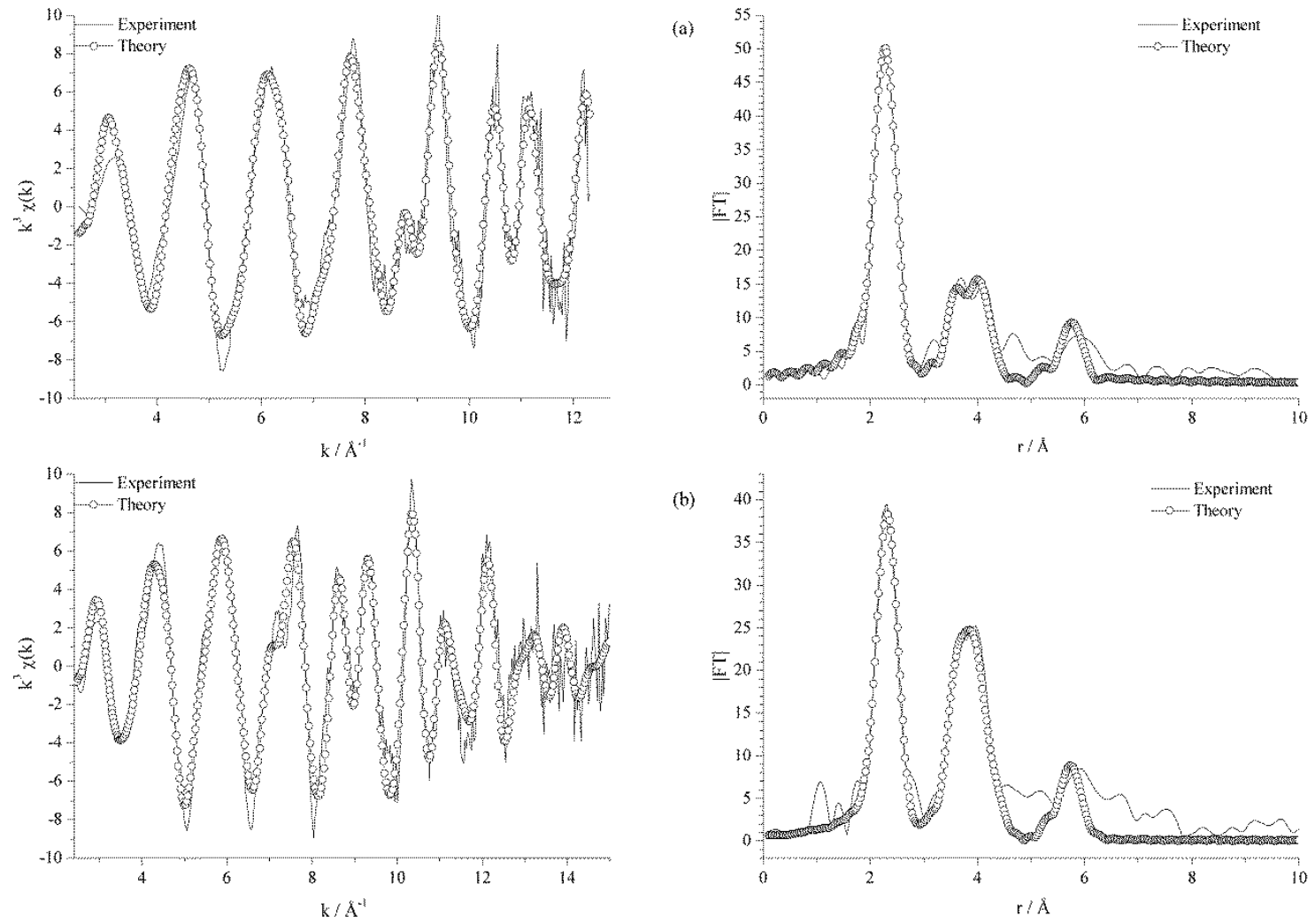

Figure 5. EXAFS (left) and FT (right) of $\mathrm{Ba}_{2} \mathrm{Co}_{0.5} \mathrm{Zn}_{0.5} \mathrm{~S}_{3}$. (a) Co K-edge and (b) Zn K-edge. 


\begin{tabular}{|c|c|c|c|c|c|c|c|c|c|c|}
\hline \multirow{2}{*}{$\begin{array}{l}\text { Bond type } \\
\text { (occupation } \\
\text { number) }\end{array}$} & \multicolumn{2}{|c|}{$\mathrm{Ba}_{2} \mathrm{CoS}_{3}$} & \multicolumn{2}{|c|}{$\mathrm{Ba}_{2} \mathrm{Co} 0.75 \mathrm{Zn}_{0.25} \mathrm{~S}_{3}$} & \multicolumn{2}{|c|}{$\mathrm{Ba}_{2} \mathrm{Co}_{0.5} \mathrm{Zn}_{0.5} \mathrm{~S}_{3}$} & \multicolumn{2}{|c|}{$\mathrm{Ba}_{2} \mathrm{Co} 0.25 \mathrm{Zn}_{0.75} \mathrm{~S}_{3}$} & \multicolumn{2}{|c|}{$\mathrm{Ba}_{2} \mathrm{ZnS}_{3}$} \\
\hline & $r(\AA)^{(a, b)}$ & $2 \sigma^{2}\left(\AA^{2}\right)^{(c)}$ & $\mathrm{r}(\AA)$ & $2 \sigma^{2}\left(\AA^{2}\right)$ & $\mathrm{r}(\AA)$ & $2 \sigma^{2}\left(\AA^{2}\right)$ & $\mathrm{r}(\AA)$ & $2 \sigma^{2}\left(\AA^{2}\right)$ & $\mathrm{r}(\AA)$ & $2 \sigma^{2}\left(\AA^{2}\right)$ \\
\hline Co-S (4) & $2.334(3)$ & $0.0139(6)$ & $2.338(4)$ & $0.0123(7)$ & $2.334(4)$ & $0.0118(7)$ & $2.334(6)$ & $0.0109(10)$ & & \\
\hline Co-Ba (3) & $3.539(8)$ & $0.0184(10)^{(\mathrm{d})}$ & $3.533(10)$ & $0.0148(9)^{(\mathrm{d})}$ & $3.544(11)$ & $0.0165(12)^{(\mathrm{d})}$ & $3.535(18)$ & $0.0165(20)^{(\mathrm{d})}$ & & \\
\hline $\mathrm{Co}-\mathrm{Ba}(4)$ & $3.840(14)$ & $0.0184(10)^{(\mathrm{d})}$ & $3.832(18)$ & $0.0148(9)^{(\mathrm{d})}$ & $3.841(20)$ & $0.0165(12)^{(\mathrm{d})}$ & $3.815(29)$ & $0.0165(20)^{(\mathrm{d})}$ & & \\
\hline $\mathrm{Co}-\mathrm{Co}(2)$ & $4.078(16)$ & $0.0139(48)$ & $4.053(24)$ & $0.0166(105)$ & $4.066(21)$ & $0.0135(82)$ & $4.053(49)$ & $0.0193(178)$ & & \\
\hline Co-Ba (4) & $5.570(10)$ & $0.0128(19)$ & $5.570(9)$ & $0.0089(16)$ & $5.582(10)$ & $0.0091(18)$ & $5.599(15)$ & $0.0087(27)$ & & \\
\hline$E_{f}(e)$ & $-9.3(4)$ & & $-9.5(5)$ & & $-9.3(6)$ & & $-9.0(8)$ & & & \\
\hline $\mathrm{R}^{(\mathrm{f})}$ & 23.5 & & 28.0 & & 29.4 & & 38.7 & & & \\
\hline $\mathrm{FI}^{(\mathrm{g})}$ & 0.235 & & 0.355 & & 0.411 & & 0.871 & & & \\
\hline $\mathrm{Zn}-\mathrm{S}(4)$ & & & $2.366(5)$ & $0.0142(9)$ & $2.369(5)$ & $0.0148(9)$ & $2.367(4)$ & $0.0152(8)$ & $2.372(3)$ & $0.0149(6)$ \\
\hline $\mathrm{Zn}-\mathrm{Ba}(3)$ & & & $3.544(8)$ & $0.0151(8)^{(d)}$ & $3.530(7)$ & $0.0147(6)^{(\mathrm{d})}$ & $3.535(7)$ & $0.0163(7)^{(\mathrm{d})}$ & $3.538(5)$ & $0.0156(5)^{(d)}$ \\
\hline $\mathrm{Zn}-\mathrm{Ba}(4)$ & & & $3.806(9)$ & $0.0151(8)^{(\mathrm{d})}$ & $3.818(8)$ & $0.0147(6)^{(\mathrm{d})}$ & $3.808(8)$ & $0.0163(7)^{(\mathrm{d})}$ & $3.811(6)$ & $0.0156(5)^{(d)}$ \\
\hline $\mathrm{Zn}-\mathrm{Zn}(2)$ & & & $4.133(15)$ & $0.0123(34)$ & $4.129(24)$ & $0.0176(56)$ & $4.144(16)$ & $0.0158(38)$ & $4.149(14)$ & $0.0170(32)$ \\
\hline $\mathrm{Zn}-\mathrm{Ba}(4)$ & & & $5.608(11)$ & $0.0115(18)$ & $5.608(10)$ & $0.0116(17)$ & $5.614(11)$ & $0.0133(18)$ & $5.623(8)$ & $0.0132(14)$ \\
\hline $\mathrm{E}_{\mathrm{f}}$ & & & $-8.6(6)$ & & $-8.4(6)$ & & $-8.0(5)$ & & $-8.9(4)$ & \\
\hline $\mathrm{R}$ & & & 36.6 & & 33.9 & & 31.7 & & 25.3 & \\
\hline FI & & & 0.507 & & 0.428 & & 0.358 & & 0.229 & \\
\hline
\end{tabular}

Table 3. Summary of Co K-edge and $\mathrm{Zn} \mathrm{K}$-edge refined EXAFS parameters for $\mathrm{Ba}_{2} \mathrm{Co}_{1-\mathrm{x}} \mathrm{Zn}_{\mathrm{x}} \mathrm{S}_{3}$

(a) Refinement standard deviation in parentheses; ${ }^{\text {(b) }}$ estimated systematic errors in EXAFS bond lengths are $\pm 1.5 \%$ for well-defined co-ordination shells; ${ }^{(\mathrm{c})}$ Debye-Waller factor; ${ }^{(\mathrm{d})}$ constrained to be equal during refinement; ${ }^{(\mathrm{e})} \mathrm{Ef}_{\mathrm{f}}$ is a single refined parameter to reflect differences

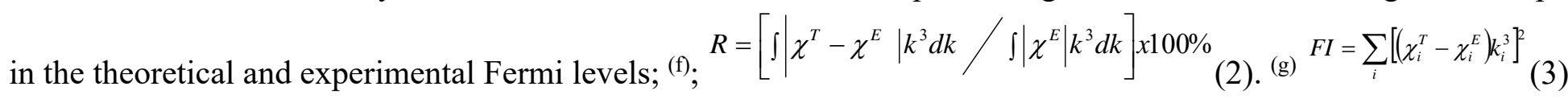




\section{Transmission Electron Microscopy}

The selected samples $\mathrm{Ba}_{2} \mathrm{CoS}_{3}, \mathrm{Ba}_{2} \mathrm{Co}_{0.75} \mathrm{Zn}_{0.25} \mathrm{~S}_{3}$ and $\mathrm{Ba}_{2} \mathrm{Co}_{0.5} \mathrm{Zn}_{0.5} \mathrm{~S}_{3}$ were examined by TEM. Figure 6 shows ED pattern for the main zone axes, which are similar for all three examined samples. All ED patterns could be indexed using the Pnam space group and unit cell parameters in Table 2. ED patterns did not exhibit any signature of ordering, superstructure or visible distortion (Figure 6). EDX analysis over a large number of crystals of $\mathrm{Ba}_{2} \mathrm{Co}_{0.75} \mathrm{Zn}_{0.25} \mathrm{~S}_{3}$ and $\mathrm{Ba}_{2} \mathrm{Co}_{0.5} \mathrm{Zn}_{0.5} \mathrm{~S}_{3}$ shows the average elemental composition is $\mathrm{Ba}_{2.27} \mathrm{Co}_{0.79} \mathrm{Zn}_{0.21} \mathrm{~S}_{3.23}$ and $\mathrm{Ba}_{2.56} \mathrm{Co}_{0.55} \mathrm{Zn}_{0.45} \mathrm{~S}_{3.62}$ correspondingly, which is in good correspondence with the nominal composition.

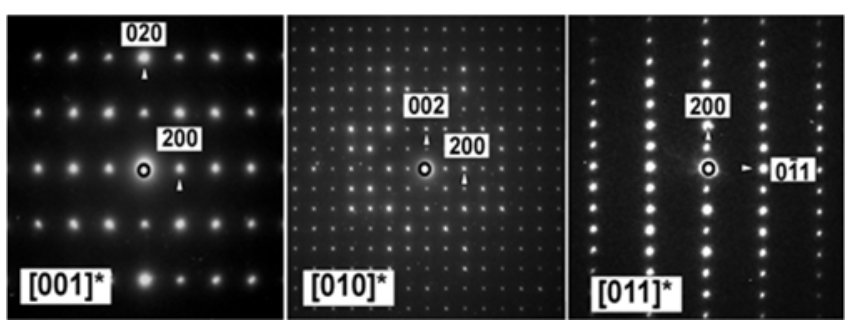

Figure 6. ED patterns of $\mathrm{Ba}_{2} \mathrm{Co}_{0.5} \mathrm{Zn}_{0.5} \mathrm{~S}_{3}$ sample along main zone axes. Identical ED patterns were observed for $\mathrm{Ba}_{2} \mathrm{Co}_{0.75} \mathrm{Zn}_{0.25} \mathrm{~S}_{3}$ and $\mathrm{Ba}_{2} \mathrm{CoS}_{3}$.

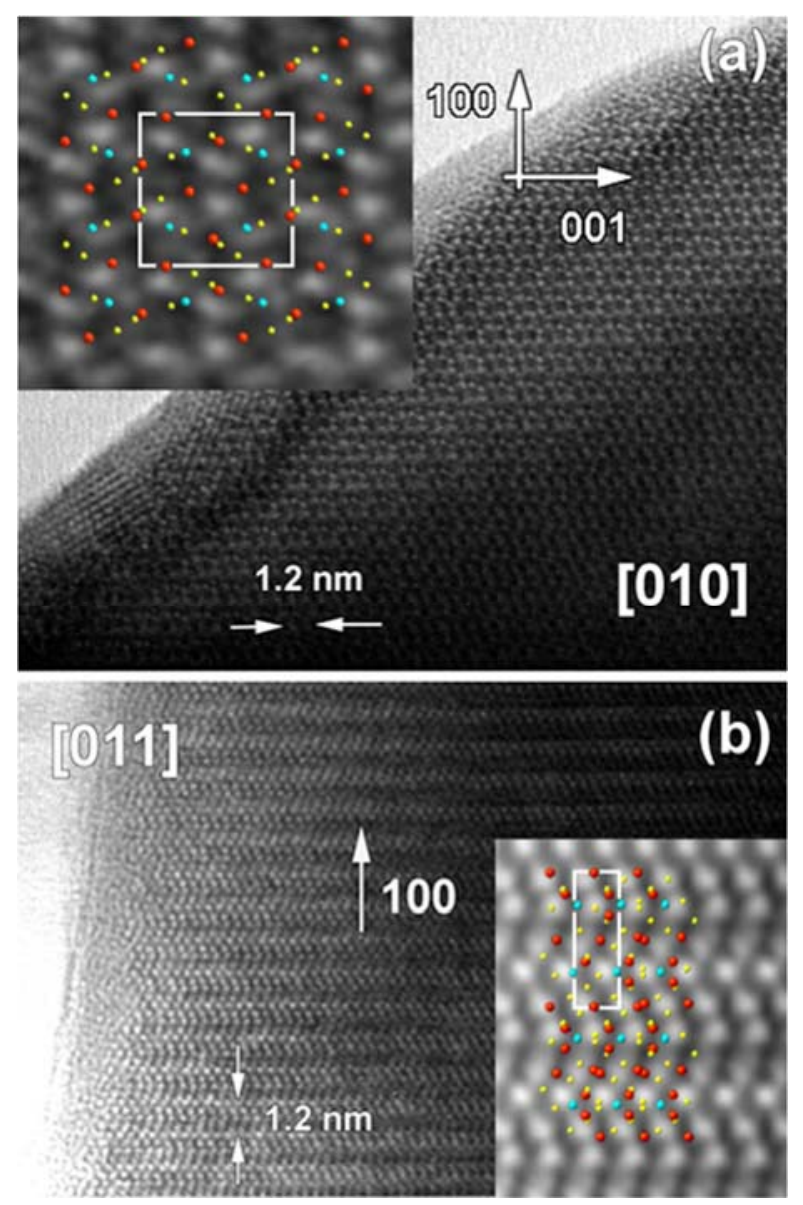


Figure 7. HRTEM images of $\mathrm{Ba}_{2} \mathrm{Co}_{0.75} \mathrm{Zn}_{0.25} \mathrm{~S}_{3}$ sample along [010] -(a) and [011] - (b) representative zone axes. In the model within the insets, red spheres represent Ba cations, blue spheres $\mathrm{Co}(\mathrm{Zn})$ cations and yellow spheres, $\mathrm{S}$ anions.

In order to obtain more structural data and evidences of possible defect structure or/and short range ordering, a HRTEM study has been performed along the most relevant [010] and [011] directions where the structure can be interpreted in the terms of $\mathrm{Ba}, \mathrm{Co}-\mathrm{Zn}$ and $\mathrm{S}$ columns. Figure 7 shows the HRTEM results for $\mathrm{Ba}_{2} \mathrm{Co}_{0.75} \mathrm{Zn}_{0.25} \mathrm{~S}_{3}$ sample. According to image simulations, based on the Pnam structural parameters obtained from neutron data (see Tables $1,2)$ brightest dots represent a channel and less bright dots in between corresponds to projection of Ba columns. Owing a detailed analysis of different areas and numbers of different crystals only a perfectly crystalline structure, free of any defects or structural modulations has been revealed. Therefore, based on all TEM measurements it can be concluded that the $\mathrm{Zn}$ is randomly and homogeneously distributed on the Co position in the $\mathrm{Ba}_{2} \mathrm{Co}_{1-x} \mathrm{Zn}_{\mathrm{x}} \mathrm{S}_{3}$ solid solution.

\section{Magnetic Susceptibility}

The increasing substitution of $\mathrm{Zn}^{2+}$ for $\mathrm{Co}^{2+}$ in $\mathrm{Ba}_{2} \mathrm{CoS}_{3}$ leads to a fragmentation of the antiferromagnetic interactions along the chains, which is expected to rapidly destroy the longrange ordering and eventually all features of $1 \mathrm{D}$ magnetism. ${ }^{26-29}$ The evolution of the magnetic susceptibility $\chi(T)$ for the smallest $\mathrm{x}$ values $(\leq 0.25)$ is shown in Fig. 8 .

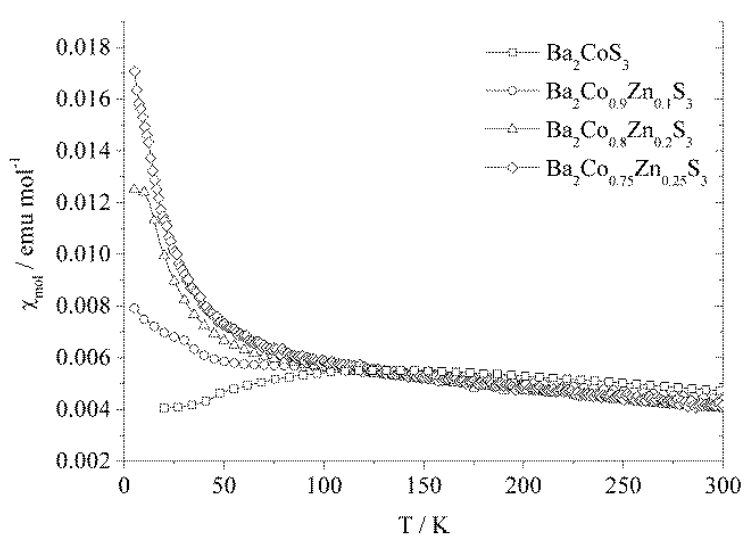




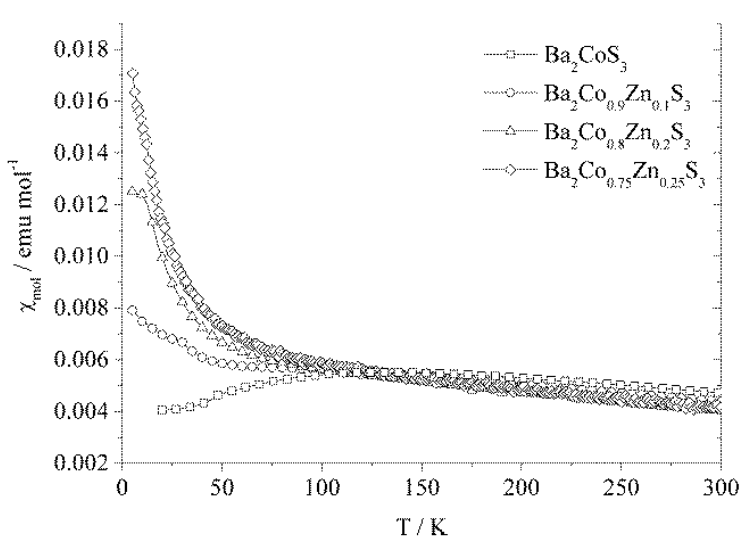

Figure 8. Susceptibility curves recorded in 100 Oe for $\mathrm{Ba}_{2} \mathrm{Co}_{1-\mathrm{x}} \mathrm{Zn}_{\mathrm{x}} \mathrm{S}_{3}(\mathrm{x}=0.1,0.2,0.25)$ and $\mathrm{Ba}_{2} \mathrm{CoS}_{3}$

The main effect is a progressive extension of the paramagnetic regime to lower temperatures, which leads to a growing Curie-like upturn. For these small $\mathrm{x}$ values, one can also detect a kink on the $\chi(\mathrm{T})$ curves, which is located around 28 and $8 \mathrm{~K}$ for $\mathrm{x}=0.1$ and 0.2 , respectively. This anomaly almost vanished for $\mathrm{x}=0.25$, and is totally absent for larger $\mathrm{x}$ values. Such a feature reminiscent of that marking the $T_{N}$ at $46 \mathrm{~K}$ for $\mathrm{x}=0$ most likely reflects the persistence of a weakened spin ordering. Its superimposition on a Curie-like background indicates an inhomogeneous magnetic response that is ascribable to the random character of the substitution.

Let us now address the impact of the substitution on the paramagnetic regime. Figure 9 shows $1 / \chi$ versus $T$ for selected $x$ values over the whole investigated range. In each case, a reasonably linear regime takes place in the high-T range (above about $200 \mathrm{~K}$ ). However, in lowdimensional compounds where magnetic fluctuations can develop up to very high temperatures, an apparent linear regime in a limited $\mathrm{T}$ range does not warrant the reliability of a simple Curie-Weiss $(\mathrm{CW})$ analysis [i.e., $1 / \chi \approx 8\left(T-\theta_{C W}\right) /\left(\mu_{e f f} / \mu_{B}\right)^{2}(4)$ in molar cgs units] to determine the effective magnetic moment $\mu_{\text {eff }}$ and the Curie-Weiss temperature $\theta_{\mathrm{CW}}$. We previously showed that this problem is present with $\mathrm{x}=0$, for which $1 \mathrm{D}$ fluctuations considerably impact the paramagnetic regime up to at least $400 \mathrm{~K} .{ }^{14}$ Only models taking explicitly this $1 \mathrm{D}$ character into account allowed us to derive the Landé factor $(\mathrm{g} \approx 2.36)$ of the $\mathrm{Co}^{2+}$ sitting at the $\mathrm{CoS}_{4}$ tetrahedra. ${ }^{14}$ 


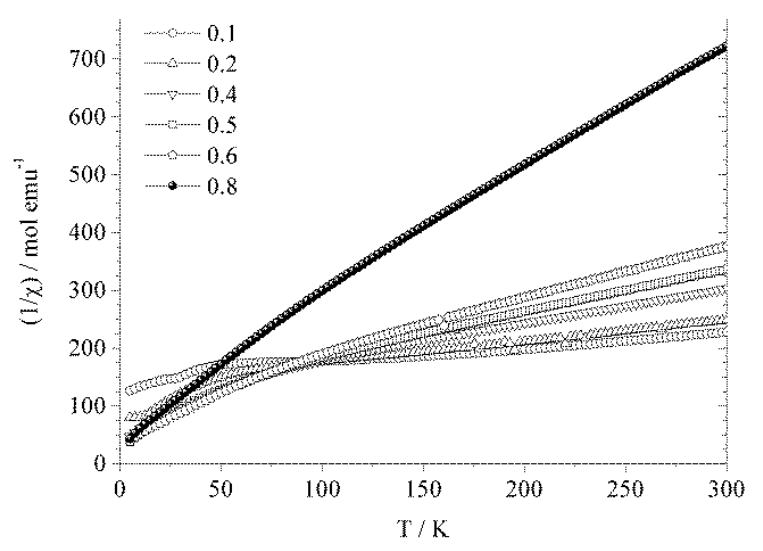

Figure 9. Reciprocal of the susceptibility, $1 / \chi$, recorded in 3000 Oe for selected samples within the $\mathrm{Ba}_{2} \mathrm{Co}_{1-\mathrm{x}} \mathrm{Zn}_{\mathrm{x}} \mathrm{S}_{3}$ series.

In the present study, we thus considered that the parameters derived from $\mathrm{CW}$ analysis must first be regarded as apparent values, noted $\mu_{\text {eff }}^{*}$ and $\theta_{C W}^{*}$. Figure 10 shows the variation of these parameters with $\mathrm{x}$, extracted from CW fitting within the range 200-300 K. As $\mathrm{x}$ is increased, one observes that both $\mu_{\text {eff }}^{*}$ an $\left|\theta_{\mathrm{CW}}^{*}\right|$ decrease, as it is expected for a dilution effect. Also shown in Fig. 10 is the expected variation of the effective moment with $\mathrm{x}$, calculated using the $\mathrm{g}=2.36$ value of $\mathrm{Co}^{2+}$ previously derived from $\mathrm{x}=0^{14}: \mu_{\text {eff }}(x)=4.6 \mu_{B} \sqrt{1-x}$. One observes that the apparent values of effective moment progressively deviate from the expected ones for the smallest $\mathrm{x}$ values $(\mathrm{x}<0.4)$, a behavior which can be ascribed to the persistence of $1 \mathrm{D}$ fluctuations up to $300 \mathrm{~K}$ for moderate substitution levels. For larger $\mathrm{x}$ values, the agreement between the calculated curve and the experimental data derived from a direct $\mathrm{CW}$ analysis is remarkably good. This suggests that the fragmentation of the Co chains for $\mathrm{x} \geq 0.4$ is enough to hinder $1 \mathrm{D}$ fluctuations and thereby make valid the $\mathrm{CW}$ relationship in our experimental $\mathrm{T}$ range $(200-300 \mathrm{~K})$. Moreover, the present data lends further support to the reliability of the value $\mathrm{g}=2.36$, since it is found to be consistent both with $1 \mathrm{D}$ models applied to $\mathrm{x}=0$ and with $\mathrm{CW}$ analysis of heavily substituted compounds. We also note that this $\mathrm{g}$ value is in line with previous results obtained for tetrahedrally coordinated $\mathrm{Co}^{2+}$ in oxides, like $\mathrm{CoAl}_{2} \mathrm{O}_{4} .^{30,31}$

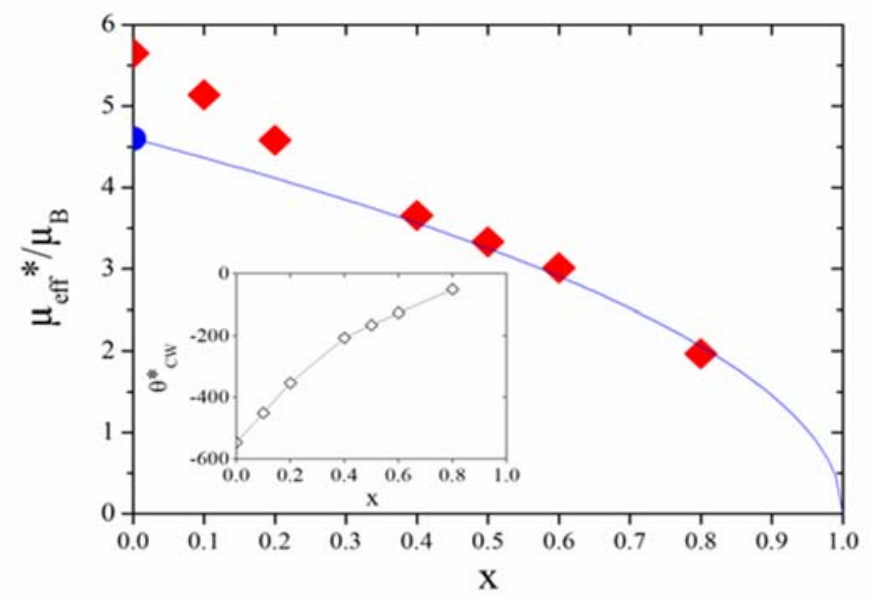


Figure 10. Apparent values of the effective magnetic moment (main panel) and of the CurieWeiss temperature (inset), as a function of $\mathrm{x}$ for samples of the $\mathrm{Ba}_{2} \mathrm{Co}_{1-\mathrm{x}} \mathrm{Zn}_{\mathrm{x}} \mathrm{S}_{3}$ series. The filled circle at $\mathrm{x}=0\left(\mu_{\mathrm{eff}}=4.6 \mu_{\mathrm{B}}\right)$ corresponds to the $\mathrm{g}$ factor of $\mathrm{Co}^{2+}(\mathrm{g}=2.36)$ previously derived from a $1 \mathrm{D}$ analysis of the unsubstituted material. ${ }^{14}$ The dashed line is the expected variation of $\mu_{\text {eff }} / \mu_{\mathrm{B}}$ resulting from dilution when considering $\mathrm{g}=2.36: \mu_{\text {eff }}(x)=4.6 \mu_{B} \sqrt{1-x}$.

To further analyse the magnetic data, let use statistical calculations to characterize quantitatively the fragmentation of the spin chains resulting from the $\mathrm{Zn}$ substitution. For $\mathrm{x}>$ 0 , the infinite Co chains break into pieces, leading to a distribution of segments of length $\mathrm{L}$ (herein expressed in terms of number of adjacent $\mathrm{Co}$ ). Considering a random distribution of $\mathrm{Zn}$, the average length of these finite Co chains, Lave, is given by the relationship: ${ }^{32} \mathrm{Lave}=(2-$ $\mathrm{x}) / \mathrm{x}$. The fast decrease of Lave as $\mathrm{x}$ increases is displayed in Fig. 11(a). One observes for instance that the vanishing of detectable magnetic ordering around $\mathrm{x} \sim 0.3$ corresponds to $\mathrm{L}_{\mathrm{ave}}$ $\sim 5$. Owing to the random nature of the $\mathrm{Co} / \mathrm{Zn}$ distribution, however, a fraction of long chains carrying a $1 \mathrm{D}$ character can persist and influence the paramagnetic susceptibility. Let us assume that a spin chain segment can still exhibit 1D features only if its length exceeds a characteristic value noted $\mathrm{L}_{\mathrm{c}}$. To analyse such a crossover, one must go beyond $\mathrm{L}_{\text {ave, }}$ and consider the distribution law of the surviving Co chains as a function of their length. The probability $\mathrm{p}(\mathrm{L}>\mathrm{Lc})$ for a given spin to belong to a chain having a length $\mathrm{L}>\mathrm{L}_{\mathrm{c}}$ can be evaluated by considering that :(i) the probability of any site to be $\mathrm{Zn}^{2+}$ is x (i.e., $1-\mathrm{x}$ for $\mathrm{Co}^{2+}$ ); (ii) A segment of length $\mathrm{L}$ is made of $\mathrm{L}$ adjacent $\mathrm{Co}^{2+}$ with at least one $\mathrm{Zn}^{2+}$ at each boundary; (iii) Once a given $\mathrm{Co}^{2+}$ is considered, the requirement is to have $(\mathrm{L}-1)$ adjacent $\mathrm{Co}^{2+}$, and there are $\mathrm{L}$ possible configurations to do so. Accordingly, the probability for a $\mathrm{Co}^{2+}$ in $\mathrm{Ba}_{2} \mathrm{Co}_{1-x} \mathrm{Zn}_{\mathrm{x}} \mathrm{S}_{3}$ to be part of a segment of length $\mathrm{L}$ is $\mathrm{Lx}^{2}(1-\mathrm{x})^{\mathrm{L}-1}$, and thus $p\left(L>L_{C}\right)(x)=\sum_{L>L c} L x^{2}(1-x)^{L-1}=(1-x)^{L_{C}}\left(1+x L_{C}\right)(5)$. This function is shown in Fig. 11(b) for several $L_{c}$ values. 


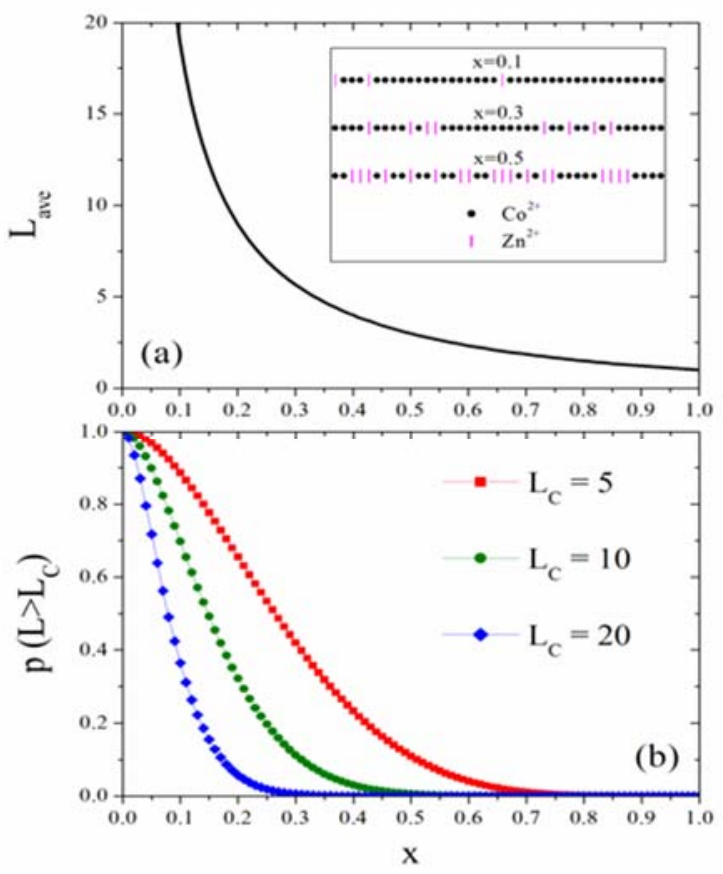

Figure 11. (a) Average length of the spin segments in $\mathrm{Ba}_{2} \mathrm{Co}_{1-\mathrm{x}} \mathrm{Zn}_{\mathrm{x}} \mathrm{S}_{3}$, given as the number of adjacent $\mathrm{Co}^{2+}$. The inset illustrates the chain breaking in the case $\mathrm{x}=0.1,0.3,0.5$. (b) Probability $\mathrm{p}(\mathrm{L}>\mathrm{Lc})$ for a given $\mathrm{Co}^{2+}$ spin to belong to a chain having a length $\mathrm{L}>\mathrm{Lc}_{\mathrm{c}}$.

Comparing figures 10 and 11 , the crossover found close to $\mathrm{x} \sim 0.4$ in the variation of the apparent effective moment indicates that only spin segments containing more than about 10 spins can generate significant effects of $1 \mathrm{D}$ fluctuations around room-temperature in the $\mathrm{Ba}_{2} \mathrm{Co}_{1-} \mathrm{ZZn}_{\mathrm{x}} \mathrm{S}_{3}$ compounds.

\section{Transport Properties}

The resistivity of the series $\mathrm{Ba}_{2} \mathrm{Co}_{1-x} \mathrm{Zn}_{\mathrm{x}} \mathrm{S}_{3}(\mathrm{x}=0.1,0.25,0.5,0.6,0.75)$ was measured using the four point probe method over the temperature range 5 - $300 \mathrm{~K}$ (figure 12). All of the samples are semiconductors, indicated by the increase in resistivity as the temperature is reduced as well as the values for the resistivity, which fall well within the range expected for semiconductors and are much higher than that of $\mathrm{Ba}_{2} \mathrm{CoS}_{3}\left(10^{-1} \Omega \mathrm{cm}\right)$, considered a weak metal. It is worth noting that only a very small amount of zinc present in the system is required to change the system from a metallic-like conductor to a semiconductor. 


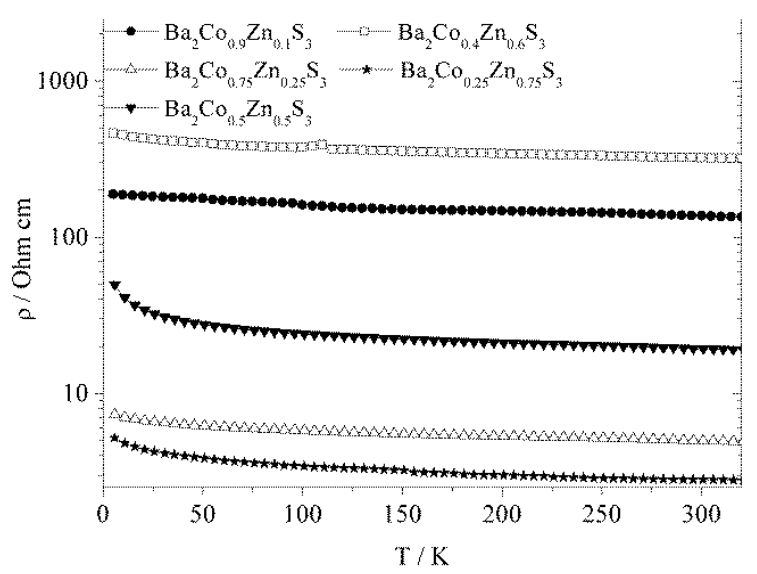

Figure 12. Resistivity of the series $\mathrm{Ba}_{2} \mathrm{Co}_{1-\mathrm{x}} \mathrm{Zn}_{\mathrm{x}} \mathrm{S}_{3}(\mathrm{x}=0.1,0.25,0.5,0.6,0.75)$

The resistivity data has been analysed using the variable range hopping model based on the equation

$\rho=\rho_{0} \exp -\left[\left(\frac{T_{0}}{T}\right)^{1 /(n+1)}\right]$

where $\rho$ is the resistivity, $\mathrm{T}$ the temperature, $\mathrm{T}_{0}$ the activation temperature and $\mathrm{n}$ the dimension of the conductance and

$T_{0}=\frac{21}{k_{B} N\left(E_{F}\right) \xi^{3}}$

with $\mathrm{k}_{\mathrm{B}}$ as the Boltzmann constant, $\mathrm{N}\left(\mathrm{EF}_{\mathrm{F}}\right)$ the density of states and $\xi$ the localisation length.

Plots of $\ln (\rho)$ against $1 / \mathrm{T}^{1 / \mathrm{n}+1}$, with $\mathrm{n}=0,1,3$ (figure 13) show that the method of conduction is three dimensional as plots of $1 / \mathrm{T}^{1 / 4}($ i.e. $\mathrm{n}=3$ ) against $\ln (\rho)$ yield straight lines. 


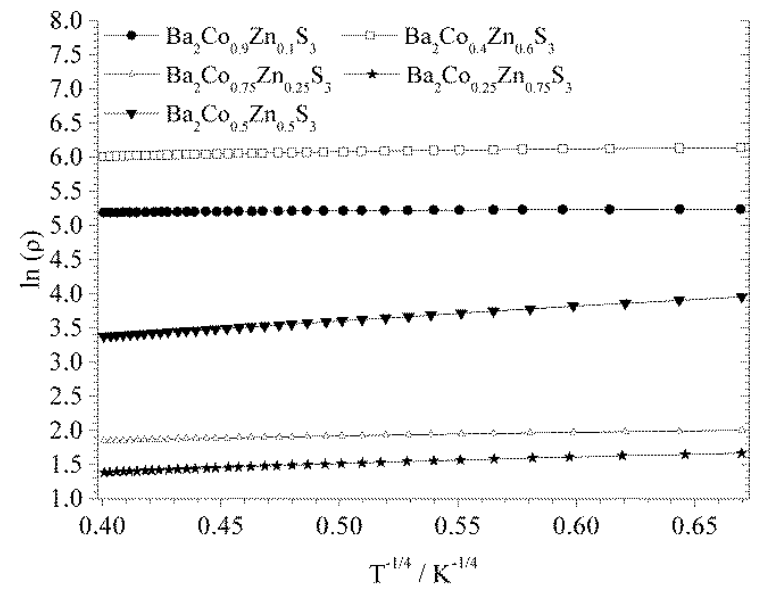

Figure 13. Arrhenius plot of resistivity data for $\mathrm{Ba}_{2} \mathrm{Co}_{1-x} \mathrm{Zn}_{\mathrm{x}} \mathrm{S}_{3}(\mathrm{x}=0.1,0.25,0.5,0.6$, 0.75 ) showing the linear dependency of $\ln (\rho)$ against $T^{-1 / 4}$ indicating $3-\mathrm{D}$ conductivity.

The linear parts of the plots of $\ln (\rho)$ against $\mathrm{T}^{-1 / 4}(5-40 \mathrm{~K})$ have been used to determine the parameters $\rho_{0}$ and $\mathrm{T}_{0}$ for $\mathrm{Ba}_{2} \mathrm{Co}_{1-\mathrm{x}} \mathrm{Zn}_{\mathrm{x}} \mathrm{S}_{3}(\mathrm{x}=0.1,0.25,0.5,0.6,0.75)$ and it showed that there is no pattern in the values of the resistivity related to the content of zinc or to the parameters $\rho_{0}$ and $\mathrm{T}_{0}$. However, due to the low compactness of the samples this fit has to be treated with caution and is not reported here.

The resistivity was measured in the presence of an external magnetic field to determine the magnetoresistance.

The resistivity of the samples $\mathrm{Ba}_{2} \mathrm{Co}_{1-\mathrm{x}} \mathrm{Zn}_{\mathrm{x}} \mathrm{S}_{3}(\mathrm{x}=0.1 .0 .25,0.5,0.6,0.75)$ was measured at 5 $\mathrm{K}$ in a field from 0-7 T, and the difference between the resistivity, $\rho$, at $\mathrm{H}=0$ and in the presence of an external field, $\mathrm{H}$, analysed using the ratio $\rho_{\mathrm{H}} / \rho_{\mathrm{H}=0}$ (figure 14). The magnetoresistance (MR) can be calculated from that ratio, using the relationship $M R=-100 \times\left(1-\rho_{H} / \rho_{H}=0\right)$.

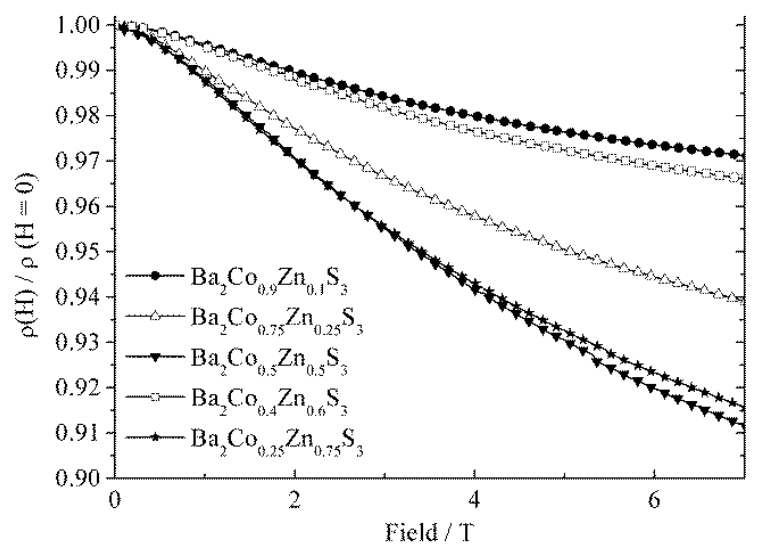

Figure 14. Isothermal resistivity curves for $\mathrm{Ba}_{2} \mathrm{Co}_{1-\mathrm{x}} \mathrm{Zn}_{\mathrm{x}} \mathrm{S}_{3}(\mathrm{x}=0.1 .0 .25,0.5,0.6,0.75)$ measured at $5 \mathrm{~K}$ 
All samples show a negative magnetoresistance which absolute value is over $\mathrm{Ba}_{2} \mathrm{CoS}_{3}(\sim 1.7 \%$ at $5 \mathrm{~K}, 7 \mathrm{~T}$ ) reaching a maximum value of $\sim 9 \%$ for $\mathrm{Ba}_{2} \mathrm{Co}_{0.5} \mathrm{Zn}_{0.5} \mathrm{~S}_{3}$ (table 4 ).

\begin{tabular}{l|l|l}
\hline $\mathrm{x}$ & $\mathrm{MR}$ & $(\%)$ \\
\hline 0.1 & 3 \\
0.25 & 6 \\
0.5 & 9 \\
0.6 & 3.5 \\
0.75 & 8.5 \\
\hline
\end{tabular}

Table 4. Absolute value of $\mathrm{MR}$ for $\mathrm{Ba}_{2} \mathrm{Co}_{1-\mathrm{x}} \mathrm{Zn}_{\mathrm{x}} \mathrm{S}_{3}(\mathrm{x}=0.1 .0 .25,0.5,0.6,0.75)$ at $5 \mathrm{~K}, 7 \mathrm{~T}$.

As with the resistivity there is no trend associated with the magnetoresistance in relation to the amount of zinc present. There is also no relation between the values of resistivity, $\rho$, and the magnetoresistance.

To investigate further the lack of a clear dependency of the transport properties on the stoichiometry of the compounds, the magnetoresistance of two different samples for each of the two sulfides $\mathrm{Ba}_{2} \mathrm{Co} 0.75 \mathrm{Zn} 0.25 \mathrm{~S}_{3}$ and $\mathrm{Ba}_{2} \mathrm{Co} 0.4 \mathrm{Zn}_{0.6} \mathrm{~S}_{3}$ were analysed (figure 15).

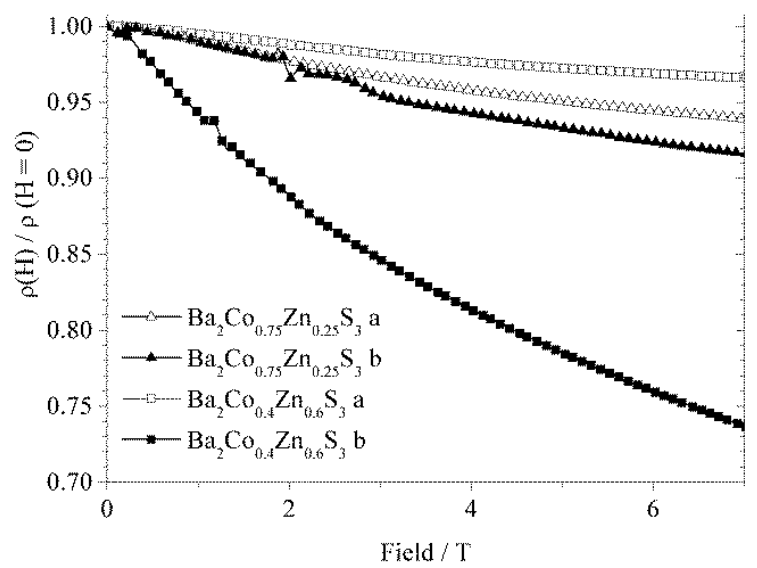

Figure 15. Isothermal resistivity ratio as a function of magnetic field for two samples (a and $b$ ) of $\mathrm{Ba}_{2} \mathrm{Co} 0.75 \mathrm{Zn} 0.25 \mathrm{~S}_{3}$ and $\mathrm{Ba}_{2} \mathrm{Co} 0.4 \mathrm{Zn}_{0.6} \mathrm{~S}_{3}$ measured at $5 \mathrm{~K}$ 
In a $7 \mathrm{~T}$ field at $5 \mathrm{~K}$, the magnetoresistance for the second sample of $\mathrm{Ba}_{2} \mathrm{Co}_{0.4} \mathrm{Zn}_{0.6} \mathrm{~S}_{3}$ was found to be quite high, $|\mathrm{MR}|>25 \%$, a 7 times increase on the value for the first sample measured. The difference between the magnetoresistance of the two $\mathrm{Ba}_{2} \mathrm{Co}_{0.75} \mathrm{Zn}_{0.25} \mathrm{~S}_{3}$ samples is smaller but still significant. The discrepancies between the magnetoresistance, seen for samples of the same stoichiometry, suggest that the origin of the magnetoresistance in $\mathrm{Ba}_{2} \mathrm{Co}_{1-x} \mathrm{Zn}_{\mathrm{x}} \mathrm{S}_{3}$ may not be intrinsic to the grains, but rather due to extrinsic parameters such as particle size and conditions for sample preparation which are affecting the grain boundaries. Another factor that may influence the magnetoresistance may be the sulfur stoichiometry, which is difficult to control during synthesis and also hard to determine accurately. To explore this hypothesis further it would be necessary to measure the magnetoresistance of compounds with strictly controlled sulphur stoichiometry and particle size and identify possible trends. The gradual decrease of $|M R|$ with temperature excludes any structural or electronic transitions as the origin of this phenomenon in $\mathrm{Ba}_{2} \mathrm{Co}_{1-\mathrm{x}} \mathrm{Zn}_{\mathrm{x}} \mathrm{S}_{3}$.

\section{Conclusion}

The series $\mathrm{Ba}_{2} \mathrm{Co}_{1-\mathrm{x}} \mathrm{Zn}_{\mathrm{x}} \mathrm{S}_{3}(\mathrm{x}=0.1,0.2,0.25,0.4,0.5,0.6,0.75,0.8)$ has been successfully synthesised. NPD, XAS and TEM were used to analyse the structure and confirmed that the solid solution maintain the structure of the end members, $\mathrm{Ba}_{2} \mathrm{CoS}_{3}$ and $\mathrm{Ba}_{2} \mathrm{ZnS}_{3}$, with zinc and cobalt randomly distributed across the same crystallographic site.

Analysis of the properties of the series shows that the compounds are paramagnetic down to the base temperature $(5 \mathrm{~K})$ for $\mathrm{x}>0.25$, and that a pure Curie Weiss regime is recovered around room temperature for $\mathrm{x} \geq 0.4$. This latter crossover is shown to correspond to a situation where the great majority of the finite spin chains are made of less than about 10 adjacent $\mathrm{Co}^{2+}$ cations. It must also be emphasized that the individual effective moment of $\mathrm{Co}^{2+}$ presently found in these $\mathrm{Zn}$ substituted compounds is in very good agreement with the value previously derived when using $1 \mathrm{D}$ models in the case of $\mathrm{x}=0 .{ }^{14}$ Resistivity measurements show that all the compounds are semiconductors with variable-range-hopping as the method of conduction. The negative magnetoresistance of $\mathrm{Ba}_{2} \mathrm{CoS}_{3}$ is generally improved by the $\mathrm{Zn}^{2+} / \mathrm{Co}^{2+}$ substitution, with values of $-6 \%$ for $\mathrm{Ba}_{2} \mathrm{Co}_{0.75} \mathrm{Zn}_{0.25} \mathrm{~S}_{3}$, - 9\% for $\mathrm{Ba}_{2} \mathrm{Co}_{0.5} \mathrm{Zn}_{0.5} \mathrm{~S}_{3}$ and $-8 \%$ for $\mathrm{Ba}_{2} \mathrm{Co}_{0.25} \mathrm{Zn}_{0.75} \mathrm{~S}_{3}$. However, there does not seem to be a correlation between the values of the resistivity and the magnetoresistance and the content of $\mathrm{Zn}^{2+}$, suggesting that transport properties might be linked more closely to extrinsic properties such as grain size, grain contact and density.

Supporting Information: listing of Rietveld refinement against neutron diffraction data for $\mathrm{Ba}_{2} \mathrm{Co}_{0.5} \mathrm{Zn}_{0.5} \mathrm{~S}_{3}$ (Figure $\mathrm{S} 1$ ), Atomic positions, thermal parameters and fractional occupancies for $\mathrm{Ba}_{2} \mathrm{Co}_{0.5} \mathrm{Zn}_{0.5} \mathrm{~S}_{3}$ (Table S1), Co K-edge EXAFS (left) and FT (right) of (a) $\mathrm{Ba}_{2} \mathrm{CoS}_{3}$ (b) $\mathrm{Ba}_{2} \mathrm{Co}_{0.75} \mathrm{Zn}_{0.25} \mathrm{~S}_{3}$ (c) $\mathrm{Ba}_{2} \mathrm{Co}_{0.5} \mathrm{Zn}_{0.5} \mathrm{~S}_{3}$ and (d) $\mathrm{Ba}_{2} \mathrm{Co}_{0.25} \mathrm{Zn}_{0.75} \mathrm{~S}_{3}$ (Figure S2) and Zn K-edge 
EXAFS (left) and FT (right) of (a) $\mathrm{Ba}_{2} \mathrm{ZnS}_{3}$ (b) $\mathrm{Ba}_{2} \mathrm{Co}_{0.25} \mathrm{Zn}_{0.75} \mathrm{~S}_{3}$ (c) $\mathrm{Ba}_{2} \mathrm{Co}_{0.5} \mathrm{Zn}_{0.5} \mathrm{~S}_{3}$ and (d) $\mathrm{Ba}_{2} \mathrm{Co}_{0.75} \mathrm{Zn}_{0.25} \mathrm{~S}_{3}$ (Figure $\mathrm{S} 3$ ). 


\section{References}

(1) Barnes, A. D. J.; Prior, T. J.; Francesconi, M. G. Zeolite-like nitride-chlorides with a predicted topology. Chem. Commun., 2007, 4638-4640.

(2) De Jongh, L. J.; Miedema, A. R. Experiments on simple magnetic model systems. Adv. Phys., 1974, 23, 1-260.

(3) Iglesias, J. E.; Pachali, K. E.; Steinfink H. Structural chemistry of $\mathrm{Ba}_{2} \mathrm{CdS}_{3}, \mathrm{Ba}_{2} \mathrm{CdSe}_{3}, \mathrm{BaCdS}_{2}$, $\mathrm{BaCu}_{2} \mathrm{~S}_{2}$ and $\mathrm{BaCu}_{2} \mathrm{Se}_{2}$. J. Solid St. Chem., 1974, 9, 6-14.

(4) Rad, H. D.; Hoppe, R. On thiomercurates. 2. $\mathrm{Ba}_{2} \mathrm{HgS}_{3}$. Z. Anorg. Allg. Chem. 1981, 483, 7-17.

(5) Greaney, M. A.; Ramanujachary, K. V.; Teweldemedhin, Z.; Greenblatt, M. Studies on the Linear Chain Antiferromagnets: $\mathrm{Ba}_{2} \mathrm{MnX}_{3}(\mathrm{X}=\mathrm{S}, \mathrm{Se}, \mathrm{Te})$ and Their Solid Solutions. J. Solid St. Chem., 1993, 107, 554-562.

(6) Baikie, T.; Hardy, V.; Maignan, A.; Francesconi, M. G. Negative magnetoresistance in $\mathrm{Ba}_{2} \mathrm{CoS}_{3}$. Chem. Commun., 2005, 5077-5079.

(7) Reiff, W. M.; Grey, I. E.; Fan, A.; Eliezer, Z.; Steinfink, H. The oxidation state of iron in some Ba-Fe-S phases: A Mössbauer and electrical resistivity investigation of $\mathrm{Ba}_{2} \mathrm{FeS}_{3}, \mathrm{Ba}_{7} \mathrm{Fe}_{6} \mathrm{~S}_{14}$, $\mathrm{Ba}_{6} \mathrm{Fe}_{8} \mathrm{~S}_{15}, \mathrm{BaFe}_{2} \mathrm{~S}_{3}$, and $\mathrm{Ba}_{9} \mathrm{Fe}_{16} \mathrm{~S}_{32}$. J. Solid St. Chem., 1975, 13, 32-40.

(8) v Schnering H. G.; Hoppe, R. Zur Kenntnis des $\mathrm{Ba}_{2} \mathrm{ZnS}_{3}$. Z. Anorg. Allg. Chem., 1961, 312, 99109.

(9) Hong H. Y.; Steinfink H, The crystal chemistry of phases in the Ba-Fe-S and Se systems. J. Solid St. Chem., 1972, 5, 93-104.

(10) Nakayama, N.; Kosuge, K.; Kachi, S.; Shinjo, T.; Takada, T. Magnetic-susceptibility and Mössbauer spectrum of $\mathrm{Ba}_{2} \mathrm{MS}_{3}(\mathrm{M}-\mathrm{Fe}, \mathrm{Co}, \mathrm{Mn})$. Abstr. Pap. Am. Chem. Soc., 1979, 58-58.

(11) Grey, I. E.; Steinfink, H. Crystal structure of $\mathrm{Ba}_{2} \mathrm{MnSe}_{3}$. Linear antiferromagnetism in $\mathrm{Ba}_{2} \mathrm{MnX}_{3}(\mathrm{X}=\mathrm{S}, \mathrm{Se})$. Inorg. Chem., 1971, 10, 691-696.

(12) Baikie, T.; Maignan, A.; Francesconi, M. G. Linear antiferromagnetism in $\mathrm{Ba}_{2} \mathrm{CoS}_{3}$. Chem. Commun., 2004, 836-837.

(13) Headspith, D. A.; Battle, P. D.; Francesconi, M. G. Long-range magnetic ordering in $\mathrm{Ba}_{2} \mathrm{CoS}_{3}$ : A neutron diffraction study. J. Solid St. Chem., 2007, 180, 2859-2863.

(14) Barnes, A. D. J.; Baikie, T.; Hardy, V.; Lepetit, M. B.; Maignan, A.; Young, N. A.; Francesconi, M. G. Magnetic coupling and long-range order in the spin-chain sulfide $\mathrm{Ba}_{2} \mathrm{CoS}_{3}$. J. Mater. Chem., 2006, 16, 3489-3502.

(15) Harrison, M. R.; Hardy, V.; Maignan, A.; Francesconi, M. G. Increase in magnetoresistivity in $\mathrm{Ba}_{2} \mathrm{CoS}_{3}$ via $\mathrm{Zn}^{2+} / \mathrm{Co}^{2+}$ substitution. Chem. Commun., 2009, 2214-2216.

(16) Binsted N., "PAXAS: Program for the Analysis of X-ray Absorption Spectra", The University of Southampton, 1988.

(17) Tenderholt, A.; Hedman, B.; Hodgson, K. O., PySpline: A modern, cross-platform program for the processing of raw averaged XAS edge and EXAFS data, AIP Conf. Proc. 2007, 882, 105-107.

(18) Binsted, N. "EXCURV98", CCLRC Daresbury Laboratory Computer Program, CCLRC, Daresbury Laboratory, U.K.: 1998.

(19) Petzel, T. Calcium sulfide, strontium sulfide, and barium sulfide from the metals and hydrogen sulfide in liquid ammonia. Z. Anorg. Allg. Chem., 1973, 396, 173-177.

(20) Larson A. C.; Von Dreele, R. B. General Structure Analysis System (GSAS), Los Alamos National Laboratory Report LAUR, 2004.

(21) Toby, B. H. EXPGUI, a graphical user interface for GSAS. J. Appl. Crystallogr., 2001, 34, 210-213.

(22) Shannon, R. D.; Prewitt, C. T. Revised values of effective ionic radii. Acta Crystallogr., Sect. B: Struct. Sci., 1970, B 26, 1046-1048.

(23) Penner-Hahn, J. E. Characterization of "spectroscopically quiet" metals in biology. Coord. Chem. Rev., 2005, 249, 161-177.

(24) Ławniczak-Jabłonska, K.; Iwanowski, R. J.; Gołacki, Z.; Traverse, A.; Pizzini, S.; Fontaine, A.; Winter, I.; Hormes, J., Local electronic-structure of $\mathrm{ZnS}$ and $\mathrm{ZnSe}$ doped by $\mathrm{Mn}, \mathrm{Fe}, \mathrm{Co}$, and Ni from X-ray-absorption near-edge structure studies. Phys. Rev. B 1996, 53, 1119-1128. 
(25) Numako, C.; Nakai, I., XAFS analysis of coprecipitation of zinc by sulfide ions in an acidic solution. Spectrochim. Acta, Part B 1999, 54, 133-141.

(26) Imry, Y.; Montano, P. A.; Hone, D. Impurity effects on the three-dimensional ordering of magnetic chain systems. Phys. Rev. B 1975, 12, 253-255.

(27) Hone, D.; Montano, P. A.; Tonegawa, T.; Imry, Y. Three-dimensional ordering of impure linear-chain systems. Phys. Rev. B 1975, 12, 5141-5149.

(28) Tonegawa, T.; Shiba, H.; Pincus, P. Thermodynamics of the impure classical Heisenberg chain. Phys. Rev. B 1975, 11, 4683-4699.

(29) Theodorou, G. Magnetic susceptibility of disordered one-dimensional systems. Phys. Rev. B 1977, 16, 2264-2272.

(30) Tristan, N.; Hemberger, J.; Krimmel, A.; Krug von Nidda, H. A.; Tsurkan, V.; Loidl, A. Geometric frustration in the cubic spinels $\mathrm{MAl}_{2} \mathrm{O}_{4}(\mathrm{M}=\mathrm{Co}, \mathrm{Fe}$, and Mn). Phys. Rev. $B$ 2005, 72, 174404/1-174404/9.

(31) Melot, B. C.; Page, K.;Seshadri, R; Stoudenmire, E. M.; Balents, L.; Bergman, D. L. ; Proffen, T. Magnetic frustration on the diamond lattice of the A-site magnetic spinels $\mathrm{CoAl}_{2-\mathrm{x}} \mathrm{Ga}_{\mathrm{x}} \mathrm{O}_{4}$ : The role of lattice expansion and site disorder. Phys. Rev. B 2009, 80, 104420/1-104420/8.

(32) Stauffer, D.; Aharony, A. Introduction to Percolation Theory. Taylor \& Francis: London, 1994. 


\section{For Table of Contents Only}
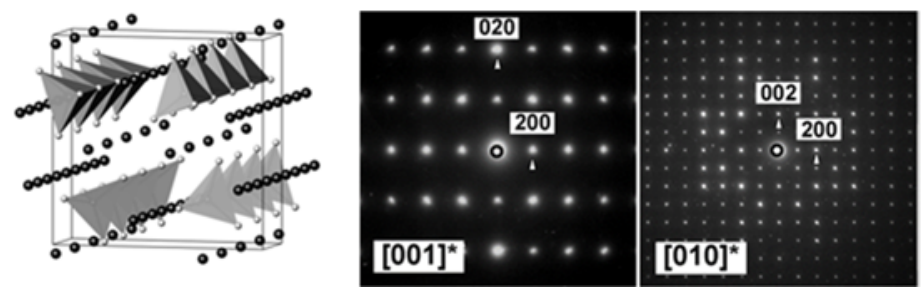

$\mathrm{Ba}_{2} \mathrm{CoS}_{3}$ shows negative magnetoresistance, which was found to be improved by $\mathrm{Zn}^{2+} / \mathrm{Co}^{2+}$ substitution. Here the investigation of the crystal structure, magnetic and transport properties of $\mathrm{Ba}_{2} \mathrm{Co}_{1-\mathrm{x}} \mathrm{Zn}_{\mathrm{x}} \mathrm{S}_{3}(0 \leq$ $\mathrm{x} \leq 0.9$ ) is reported. Substitution of $\mathrm{Zn}^{2+}$ for $\mathrm{Co}^{2+}$ leads to values of negative magnetoresistance of $\sim 9$ $\%\left(\mathrm{Ba}_{2} \mathrm{Co}_{0.5} \mathrm{Zn}_{0.5} \mathrm{~S}_{3}\right)$, removes the metallic-like behaviour of $\mathrm{Ba}_{2} \mathrm{CoS}_{3}$ and destroys the one-dimensional antiferromagnetic behaviour of $\mathrm{Ba}_{2} \mathrm{CoS}_{3}$, leading to paramagnetic behaviour. 